\title{
The Dynamics of Investment, Payout and Debt*
}

\author{
Bart M. Lambrecht \\ Cambridge Judge Business School and CEPR \\ Stewart C. Myers \\ MIT Sloan School of Management and NBER
}

26 January 2017

\begin{abstract}
We develop a dynamic agency model of a public corporation. Managers underinvest because of risk aversion. They smooth rents and payout. They do not exploit interest tax shields fully. The interactions of investment, debt and payout decisions can change drastically depending on managers' preferences. Managers with power utility set investment, debt and payout proportional to the firm's net worth, generating a constant (possibly negative) net debt ratio. With exponential utility, investment decisions are separated from decisions about debt and payout. More profitable firms become cash cows and less profitable firms accumulate debt, as in a pecking order model.

Keywords: payout, investment, financing policy, agency (JEL: G31,G32)
\end{abstract}

${ }^{*}$ We thank V. Acharya, I. Goldstein (editor), J. Huang, E. Morellec (discussant), B. Hartman-Glaser (discussant), J. Rochet (discussant), R. Gibbons, J. Pontiff, A. Thakor and two referees for insightful comments or discussions. We also thank seminar participants at the Universities of Cambridge, Cardiff, Durham, Essex and York, the Vienna University of Economics and Business, Washington University St. Louis and participants at the Cambridge-Princeton, AFA, EFA, WFA and CEPR Gerszensee meetings. Comments can be sent to Bart Lambrecht (b.lambrecht@jbs.cam.ac.uk) or to Stewart Myers (scmyers@mit.edu). 


\section{Introduction}

How do investment, financing and payout decisions interact in a mature public corporation run by risk-averse managers? Will the managers over-invest? How agressively will they pursue interest tax shields? Will the managers adopt a target leverage ratio or a peckingorder debt policy - or is either policy possible, depending on managers' preferences? When will corporations accumulate cash and end up at negative net debt ratios? Why is payout smoothed? Can payout smoothing be reconciled with a constant target debt ratio? We address these and related questions in this paper.

Our answers include promising agency-based explanations for some corporate financing and investment patterns that may otherwise remain puzzling. For example, our models can explain why managers do not lever up to exploit interest tax shields fully, even in a ModiglianiMiller (MM) setting with perfect financial markets and no information problems or costs of financial distress. But it turns out that the financial policies adopted by risk-averse managers can change drastically, depending on assumptions about their preferences.

The managers decide on risky capital investment and set capital structure and payout policies. Their corporations can issue debt or equity at any time, but must respect an intertemporal budget constraint, which forces sources of cash (operating income plus changes in net debt) to equal uses (payout and managerial rents plus investment (CAPEX)). The budget constraint eliminates one degree of freedom. For example, once CAPEX, payout and rents are set, the required amount of borrowing follows directly from the budget constraint.

We set out a general dynamic agency model in Section 2. We find that managers underinvest because of risk aversion. This result differs from most prior agency theory, which assumes that managers over-invest because of private benefits or personal gains from empirebuilding.

Payout and rents are tied together by the governance constraint and move together over 
time. The equation linking payout and rents depends on whether shareholders would choose to close the firm or run it as a going concern. Corporate taxes relax the governance constraint because rents are tax-deductible. Rents create valuable tax shields, which increase rents relative to payout.

Managers smooth rents, and therefore payout, for two reasons. First, we assume decreasing returns from rent extraction. Therefore volatile rents are inefficient. Second, risk aversion causes rent smoothing because managers try to equalize the marginal utility of rents over time. Hennessy and Whited (2007, p. 1737) note that structural models of investment, payout and borrowing "[overshoot] the variance of corporate cash distributions. ... [W]e still lack a theoretical rationale for dividend smoothing resulting from optimizing behavior." We say that payout smoothing results from the managers' optimizing behavior in a dynamic agency setting.

Risk aversion and decreasing returns to rent extraction each imply that managers will use a mix of debt and equity financing, even when shareholders would prefer the firm to borrow as much as possible. We explain why managers do not swap debt for equity in order to exploit interest tax shields fully. Once managers optimize, they see the net marginal expected utility from an additional dollar of debt as zero, even when shareholders see the NPV of that extra debt as positive.

We clarify how debt disciplines managers. The discipline does not operate in the short run by diverting cash flow to debt service. But a higher debt level reduces the future rents that the managers can extract. Therefore discipline comes from the managers' optimal dynamic response to current and future debt levels. 


\subsection{Closed-form solutions}

Sections 3 and 4 present two closed-form solutions of the general model. The solutions are derived in continuous time. All the general results from section 2 hold, but the nature of the interactions between investment, payout and financing policies depends on the managers' assumed utility function.

Section 3 assumes that the coalition of managers acts according to power utility and therefore displays constant relative risk aversion (CRRA). With power utility, CAPEX, borrowing, rent and payout are all interdependent. The firm's capital stock, net debt level and its flow of payout and rents all end up proportional to net worth. In good times, the firm expands. It invests more, issues more debt and pays out more to shareholders. Managers also take more rents. In bad times the firm contracts, moving back down its expansion path. All changes are proportional to net worth, so that the net debt ratio is constant.1 The ratios of CAPEX, payout and rents to net worth are likewise constant.

We explore what determines the net debt ratio. It can be negative if the corporate tax rate is low, managers' level of risk aversion is high or investment is sufficiently risky. (A negative net debt ratio means that the firm is a net lender.)

The CRRA model generates other interesting results. For example, taxes reduce risk for managers and increase investment. Managers underinvest, except in a regime where profitability is low and the firm should be liquidated under a first-best policy.

Section 4 derives an alternative closed-form solution assuming negative exponential utility, that is, constant absolute risk aversion (CARA). In this case debt and net worth move in opposite directions. In bad times the firm borrows more and depletes its net worth. Lenders close the firm when it is on the cusp of insolvency and, in the absence of bankruptcy costs, fully

\footnotetext{
${ }^{1}$ In our continuous-time setting, debt is safe, because net worth never becomes negative. Safe debt allows us to investigate the interactions of investment, borrowing, payout and rents in the closed-form solution.
} 
recover their money. This net-worth covenant keeps debt safe, allows a closed-form analysis and facilitates comparison with the CRRA case.

All general results from section 2 hold in the CARA model, but CAPEX decisions are independent of rent, payout and borrowing decisions. The stock of capital is constant if investment opportunities are constant. Payout and rents include a fixed component, but also respond to changes in net worth. Decisions about payout plus rents and borrowing interact. In good (bad) times, the firm accumulates (depletes) net worth and pays down (issues more) debt. Firms that perform well turn into cash cows, leaving more and more interest tax shields unexploited. Unprofitable firms pile up debt and are eventually closed down by creditors.

Thus our CARA model does not generate a meaningful target debt ratio. Instead debt becomes a short-run shock absorber, as in a pecking-order model. Changes in debt soak up most of the fluctuations in operating income.

Different specifications of managers' preferences therefore produce dramatically different predictions about the major corporate financial decisions and how they interact. Power utility generates results that are consistent with a trade-off theory of capital structure. Exponential utility leads to results consistent with the pecking-order theory. With power utility, investment, debt and payout are interdependent, but with exponential utility managers separate investment from financing decisions. We believe that the contrasts between our two closedform models' results are original and important.

\subsection{Previous literature}

The managers in our agency model face a personal optimization problem similar to the problem faced by an individual investor who allocates wealth between consumption and risky investment. Our managers take rents as consumption. They co-invest with outside shareholders in a risky asset, the firm's capital stock. They can also use corporate borrowing or 
lending to finance investment and to smooth or shift rents and payout over time. Key papers on intertemporal consumption and portfolio selection include Merton (1969, 1971), Caballero (1990), Campbell and Viceira (1999, 2002) and Angeletos and Calvet (2005, 2006).

The corporate-finance literature on investment, payout and borrowing decisions is of course enormous. But there is only a short list of models that track the joint dynamics of all three decisions. See Strebulaev and Whited (2012) and Sannikov (2013) for comprehensive surveys. As far as we know ours is the only investigation of these decisions that is a fully dynamic model, incorporates taxes, but is based on agency behavior by risk-averse managers rather than financial frictions or imperfect financial markets.

Research papers that focus on all three decisions about investment, payout and borrowing include Hennessy and Whited (2005, 2007), Gryglewicz (2011), DeAngelo, DeAngelo, and Whited (2011), Bolton, Chen, and Wang (2011), Décamps, Mariotti, Rochet, and Villeneuve (2011), and Décamps, Gryglewicz, Morellec, and Villeneuve (2016). These papers assume that risk-neutral managers maximize market value. They investigate how taxes and transaction and adjustment costs affect dynamics. We assume risk-averse managers and do not invoke transaction costs, adjustment costs or other financial frictions.

These models usually leave payout as the residual. For example, DeAngelo, DeAngelo, and Whited (2011) assume that the firm is free to restrict payout to pay down debt or to increase cash holdings as a reserve for future investment. This assumption makes sense if payout is value-irrelevant and managers are risk-neutral. We assume that payout decisions are valueirrelevant for shareholders, but not for managers, because payout is tied to managers' rents and the managers are risk-averse. Consequently payout is not a residual but an important decision variable, as it is in practice. For example, survey evidence by Brav, Graham, Harvey, and Michaely (2005) shows that for executives, maintaining the dividend level is as important as investment decisions. Dividends (see Lintner (1956)) and total payout (see Skinner (2008)) 
are in practice much smoother than net income over time, at least for mature corporations that make regular payouts to shareholders.

In Bolton, Chen and Wang (2011), firms pay out cash only when cash holdings are large, so that the shadow price of cash held for future investment is small and the costs of holding cash become burdensome. In Décamps et al. (2011, 2016), the costs of holding cash are interpreted as a free cash flow problem (e.g. managers with access to cash take some of it as private benefits). The objective assumed in this paper is still market-value maximization, however. In Gryglewicz (2011), the firm is concerned about insolvency and lack of liquidity in distress. Therefore, no payout occurs as long as cash reserves are below a target level, but any cash above the target is paid out. In our model, payout cannot be a residual, because managers maximize the utility of their rents, and payout follows rents.

Few dynamic models introduce meaningful agency issues. Zwiebel (1996) derives a dynamically consistent model of capital structure as the optimal response of partially entrenched, risk-neutral managers who always want to invest but also fear takeovers. Managers voluntarily issue risky debt, accepting bankruptcy risk as a way of committing to forgo bad investments. Morellec (2004) develops a real-options model in which risk-neutral managers want to invest and also to retain control. Managers avoid control challenges by limiting negative-NPV investment. Our paper takes a different tack, assuming risk-averse managers, who end up investing less than the value-maximizing amount.

DeMarzo, Fishman, He, and Wang (2012) consider investment and payout as results of an optimal contract between risk-neutral shareholders as principals and a risk-neutral manager. The firm builds up a cash reserve to finance investment and pays out dividends when the cash reserve reaches a maximum level. Capital structure decisions are not modeled. We do not solve for an optimal contract, but assume that the (risk-averse) managers of a public corporation act in their self-interest, subject to a governance constraint. 
Morellec, Nikolov, and Schürhoff (2012) assume that risk-neutral managers' and shareholders' interests are aligned, except for the managers' ability to capture a fraction of cash flow to equity as private benefits. They explore the dynamics of capital structure, including default and rebalancing strategies, but hold investment fixed. Our model does not include default, but investment is endogenous. Our managers are risk-averse.

Lambrecht and Myers (2007, 2008) and Jin and Myers (2006) use an agency model like this paper's, but assume that managers are risk-neutral. They focus on narrower issues, including takeovers, once-and-for-all investment or disinvestment decisions, and risk-shifting when the firm is not transparent to outside investors.

This paper builds on Lambrecht and Myers (2012), who focused on payout policy. They showed that payout is smoothed because rents are smoothed: the governance constraint forces payout to follow rents. Changes in debt soak up transitory income shocks and accommodate the gradual adjustment of rents and payout to changes in permanent income. But the role of debt as a shock absorber in Lambrecht and Myers (2012) was not surprising, because they

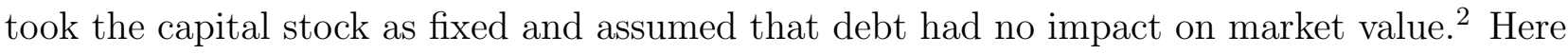
we make investment endogenous and introduce valuable interest and rent tax shields. Also Lambrecht and Myers (2012) formulate all results in discrete time for negative exponential utility. Here we generalize several important results to any utility function and any stochastic process for profitability. We derive closed-form solutions in continuous time for power utility as well as for negative exponential utility and analyze how managers' preferences affect corporate financial policies.

\footnotetext{
${ }^{2}$ Lambrecht and Myers (2012) did comment on taxes, but considered the effects of interest tax shields only in a Miller (1977) equilibrium in which the tax shields make no net addition to the market value of the firm.
} 


\section{The general model}

This section sets out our model of CAPEX, borrowing, payout and rents in its most general form. We start by valuing the firm if it were run by risk-neutral shareholders, then introduce risk-averse managers. We specify the managers' objective, the governance constraint, the budget $($ sources $=$ uses) constraint and a no-Ponzi constraint that prevents runaway borrowing and ensures finite claim values. We do not solve the model until Sections 3 and 4 below. We can nevertheless derive important results from the model's constraints and first-order conditions. For example, the general model implies that managers will limit debt even when additional borrowing would capture valuable interest tax shields.

\section{$2.1 \quad$ Risk-neutral case}

Consider a firm run by risk-neutral shareholders who seek to maximize market value. We assume that the firm is profitable and expects to generate cash for payout and managerial rents. The budget constraint is:

$$
D_{t}=D_{t-h} e^{\rho h}+K_{t}-K_{t-h} e^{\pi_{t} h}+\Psi_{t}+h p_{t}+\tau\left[K_{t-h}\left(e^{\pi_{t} h}-1\right)-D_{t-h}\left(e^{\rho h}-1\right)-\Psi_{t}\right]
$$

$D_{t}$ is net debt. If $D_{t}<0$, the firm is a net lender. Interest is compounded continuously at the risk-free rate $\rho$ over the time interval $h$, which is the time between payouts to shareholders.$^{3}$ We do not introduce default risk here, but will show that debt is safe in the closed-form solutions below.

The firm's capital stock $K_{t}$, which is fixed one period in advance, generates a stochastic gross return on capital at $t+h$ equal to $e^{\pi_{t+h} h}$, where $\pi_{t}$ is a stochastic profit rate that is net of capital depreciation. $\pi_{t}$ depends on exogenous demand shocks.

\footnotetext{
${ }^{3}$ Continuous compounding will allow for a straightforward transition to the continuous-time models (where $h \rightarrow 0)$ solved in sections 3 and 4 below.
} 
$\Psi_{t}$ is a cost function. For example, $\Psi_{t}$ can include operating costs and can be an increasing convex function of $K_{t}$ if production is subject to decreasing returns to scale. $\Psi_{t}$ can also capture adjustment costs of changing the firm's stock of capital or its outstanding debt.

$p_{t}$ is the payout rate and $h p_{t}$ is the net payout (dividends plus net repurchases) to investors at time $t$. Payouts are made at the end of each period, after the return on investment is realized. Interest is paid on start-of-period debt. Interest on debt and any costs $\Psi_{t}$ are tax-deductible, but payouts to shareholders are not. Gross profits (given in Eq. (1) by the expression between square brackets) are taxed at the corporate tax rate $\tau$.

Define $\Gamma \equiv e^{\rho h}$ and $\Pi_{t} \equiv e^{\pi_{t} h}$. Rearranging Eq. (1) gives:

$$
\begin{aligned}
K_{t}+h p_{t}+(1-\tau) \Psi_{t}-D_{t} & =K_{t-h} \Pi_{t}-\Gamma D_{t-h}-\tau\left[K_{t-h}\left(\Pi_{t}-1\right)-D_{t-h}(\Gamma-1)\right] \\
& =K_{t-h}\left[\Pi_{t}(1-\tau)+\tau\right]-D_{t-h}[\Gamma(1-\tau)+\tau] \equiv N_{t}
\end{aligned}
$$

where $N_{t}$ is the net worth of the firm at time $t$. Eq. (3) shows that the net worth $\left(N_{t}\right)$ and net debt $\left(D_{t}\right)$ are used to finance the stock of risky capital $K_{t}$, the after-tax costs $(1-\tau) \Psi_{t}$ and the payout to shareholders $h p_{t}$.

For risk-neutral investor-managers, the market value of the equity is the present value of current and future expected payout:

$$
F_{t}=E_{t}\left[\sum_{j=0}^{\infty} e^{j \rho h} h p_{t+j h}\right]
$$

where $h p_{t+j h}$ is determined by the budget constraint Eq. (1). f $^{-}$

Define the market discount factor by $\beta \equiv e^{-\rho h}$ and the after-tax free cash flow from operations by $C F_{t}^{*} \equiv K_{t-h}\left[\Pi_{t}(1-\tau)+\tau\right]-(1-\tau) \Psi_{t}-K_{t}$. Substituting the budget constraint

\footnotetext{
${ }^{4}$ Our exposition in this section assumes that the firm operates forever and that its debt is safe. These assumptions hold in the closed-form solution in section 3 it is always optimal for managers to keep the firm as a going concern and to manage debt so that default is avoided. Section 4 presents a closed-form solution for a firm that may be shut down by a solvency (positive net worth) covenant imposed by lenders. The firm may not operate forever, but the covenant protects lenders and assures that debt is safe.
} 
Eq. (1) into Eq. (4) gives the market value of the equity as:

$$
\begin{aligned}
F_{t} & =E_{t}\left[\sum_{j=0}^{\infty} \beta^{j} C F_{t+j h}^{*}\right]-(\Gamma(1-\tau)+\tau) D_{t-h}+E_{t}\left[\sum_{j=0}^{\infty} \beta^{j} D_{t+j h}(1-\beta[\Gamma(1-\tau)+\tau])(\$)\right. \\
& \equiv V_{t}-(\Gamma(1-\tau)+\tau) D_{t-h}+T_{t}
\end{aligned}
$$

The first term in Eq. (6) is the value of the unlevered firm $\left(V_{t}\right)$, which equals the present value of all (current and future) free cash flows after taxes. The second term is the amount of debt rolled over from previous period, including the after-tax cost of interest. The third term $T_{t}$ is the discounted expectation of all future interest tax shields. The tax shields contribute to firm value, just as in a textbook "MM + taxes" setting. The taxshield accrued over the interval $[t+j h, t+(j+1) h]$ is:

$$
D_{t+j h}(1-\beta[\Gamma(1-\tau)+\tau])=D_{t+j h} \tau(1-\beta)
$$

Using a first-order Taylor approximation the interest tax shield for a small time interval $h$ equals approximately $D_{t+j h} \tau \rho h$.

Risk neutral investors would choose investment $\left(K_{t}\right)$ and debt $\left(D_{t}\right)$ to maximize equity value given by Eq. (5).

Assuming that changes in debt or investment at $t$ do not affect transaction costs beyond $t+h$ (i.e. $\frac{\partial \Psi_{t+j}}{\partial D_{t}}=\frac{\partial \Psi_{t+j}}{\partial K_{t}}=0$ for $j \geq 2$, the first-order conditions with respect to $D_{t}$ and $K_{t}$ are:

$$
\begin{aligned}
& \frac{\partial F_{t}}{\partial D_{t}}=\left[1-(1-\tau) \frac{\partial \Psi_{t}}{\partial D_{t}}\right]+\beta(-1) E_{t}\left[\Gamma(1-\tau)+\tau+(1-\tau) \frac{\partial \Psi_{t+h}}{\partial D_{t}}\right]=0 \\
& \frac{\partial F_{t}}{\partial K_{t}}=\left[-1-(1-\tau) \frac{\partial \Psi_{t}}{\partial K_{t}}\right]+\beta E_{t}\left[(1-\tau) \Pi_{t+h}+\tau-(1-\tau) \frac{\partial \Psi_{t+h}}{\partial K_{t}}\right]=0
\end{aligned}
$$

Interest on debt grows at the after-tax borrowing rate $(\Gamma(1-\tau)+\tau \approx 1+h \rho(1-\tau)$ for small $h)$, while future cash flows are discounted at the market discount factor $\left(\beta=e^{-\rho h}\right)$. Absent

\footnotetext{
${ }^{5}$ We could have used payout $p_{t}$ and investment $K_{t}$ as control variables. The solution would be the same. The first-order condition with respect to $D_{t}$ allows us to infer capital-structure implications more easily.
} 
any costs of adjustment or financial distress, investors want the firm to borrow as much as possible:

$$
\frac{\partial F_{t}}{\partial D_{t}}=1-\beta[\Gamma(1-\tau)+\tau]=\tau(1-\beta)>0 \quad \text { if } \Psi_{t}=\Psi_{t+h} \equiv 0
$$

The benefit from issuing an extra dollar of debt equals the interest tax shield. With risk neutrality, an interior optimal debt level only arises if there are some costs $\left(\Psi_{t}\right)$ to offset the tax-shield benefit. When agents are risk averse, such costs are no longer required to obtain an interior optimal debt level, however.

We can also write the market value of equity as a function of the firm's net worth $N_{t}$, plus the tax shield $T_{t}$, plus the discounted expectation of all future (i.e. starting at $t+h$ ) after-tax free cash flows, minus any money invested $\left(K_{t}+(1-\tau) \Psi_{t}\right)$.

$$
F_{t}=N_{t}+T_{t}+E_{t}\left[\sum_{j=1}^{\infty} \beta^{j} C F_{t+j h}^{*}\right]-K_{t}-(1-\tau) \Psi_{t}
$$

Net worth $N_{t}$, which includes the firm's accumulated retained earnings, serves as an anchor for the firm's market value. This type of valuation equation is related to accounting valuation models that use equity book values and future expected earnings as determinants of equity prices (e.g. Ohlson (1995)).

\subsection{Risk-averse managers}

Now assume a self-interested coalition of managers that makes investment, financing and payout decisions and extracts rents from the firm. Rents are benefits over and above the managers' opportunity wages. In practice rents can come in many forms, but here we assume for simplicity that rents are cash costs to the firm. (We do not consider psychological benefits of control, for example.)

Let $s$ denote the fraction of rents that are tax-deductible ${ }^{6}$ The after-tax cost of payout and rents is therefore $p_{t} \equiv d_{t}+(1-\tau s) r_{t}$, where $d_{t}$ is the net payout to shareholders and

\footnotetext{
${ }^{6}$ Most rents, including cash payments, are tax deductible by the firm, but some may not be. For example,
} 
$p_{t}$ now represents total payout to shareholders and managers. Note that $r_{t}$ corresponds to the monetary cost of rents to the firm, which is not necessary equal to the monetary value of rents to managers. First, some rents can only be consumed hand-to-mouth. Examples include job security and perks like use of a private jet, company car or provision of VIP health insurance. An extra million spent by the company to upgrade a private jet is likely to be worth less to the manager than a $\$ 1$ million cash bonus. Moreover, the marginal value to the manager of hand-to-mouth rents is likely to decline with their size. Second, some rents, including cash bonuses, are subject to personal taxes. The marginal personal tax rate may be increasing, again decreasing marginal value to managers. Third, rent extraction may be costly to managers (see DeMarzo and Fishman (2007), for example). If so, it is reasonable to assume that the marginal cost of extraction increases in the amount of rents extracted.

Therefore we assume that the monetary equivalent of rents $r_{t}$ to managers equals $r_{t}^{\nu}$, where $\nu \leq 1$. Increasing rents by $1 \%$ raises the rents' value to managers by only $\nu \%$. When $\nu<1$, managers will seek to smooth rents. As is standard in the literature on dynamic moral hazard (see Bolton and Dewatripont (2005)) and on corporate finance we assume that risk-averse agents cannot save, invest or borrow privately $]^{7}$ This is a reasonable assumption here, as the nature of many rents (such as job security, pensions, stock options, restricted stock and hand-to-mouth rents) makes it costly or impossible for managers to vary, accelerate or delay rents by transactions on their personal accounts.

The managers are risk-averse, with a concave utility function $u\left(r_{t}^{\nu}\right)$ for the monetary value qualified ("statutory") options, which are capped to a specific amount per employee, are taxed to the employee only after they are exercised and the stock is sold. The employer is not allowed a deduction for these options. The employer is allowed a deduction for non-qualified options, but only with a delay when and if the options are exercised. See Bickley (2012) for further details.

${ }^{7}$ One notable exception that considers private saving and borrowing that is not observable to the principal is Edmans et al. (2012), who study optimal compensation in a dynamic framework. 
of rents that they extract in period $t$. At each time $t$ the infinitely-lived manager ${ }^{8}$ choose the investment, debt, payout and rents $\left(K_{t}, D_{t}, d_{t}, r_{t}\right)$ that maximize expected lifetime utility:

$$
M_{t} \equiv \max E_{t}\left[\sum_{j=0}^{\infty} \omega^{j} u\left(r_{t+j h}^{\nu}\right) h\right]
$$

where $\omega \equiv e^{-\delta h}$ and $\delta$ is managers' subjective discount rate. We assume $\delta \geq \rho$ so that managers can be more impatient than investors. For example, a manager will be more impatient if he or she contemplates mortality.

We assume that outside shareholders can force managers to share free cash flow and value: the fraction $\alpha(0<\alpha<1)$ goes to the shareholders and the rest to the managers. We interpret this sharing rule as the end result of a system of corporate governance. It can also be viewed as the result of the following repeated bargaining game. Suppose that in each period managers can make a take-it-or-leave-it offer $\left(d_{t}, r_{t}\right)$ to shareholders, who can either accept or take collective action to intervene. Acceptance means that managers keep their jobs for the next period. Intervention eliminates managers' rents $\left(r_{t+j h}=0\right.$ for all $\left.j \geq 0\right)$.

Let $S_{t}$ denote the market value of shareholders' equity. Managers set payout and rents so that shareholders are indifferent between leaving managers in place for another period and taking collective action:

$$
S_{t}=h d_{t}+\beta E_{t}\left[S_{t+h}\right]=\alpha \max \left[F_{t}, N_{t}\right] \equiv \alpha \max \left[V_{t}-(\Gamma(1-\tau)+\tau) D_{t-h}+T_{t}, N_{t}\right]
$$

The left hand of Eq. (11) is the payoff to shareholders from leaving managers in place for another period. The right hand is the payoff from intervention. Shareholders who intervene can either keep the firm as a going concern, or they can liquidate the firm to realize its net worth $N_{t} .^{9}$ However, shareholders only recover a fraction $\alpha$ of the firm value because collective

\footnotetext{
${ }^{8}$ Our model's infinite horizon is important, because it eliminates end games. Managers' financial decisions could change drastically if they knew their tenure would end at a definite future date. See Fluck (1998) and Myers (2000).

${ }^{9}$ Equation 11 does not consider optimal exercise of the put option to liquidate the firm. Instead it assumes
} 
action is costly ${ }^{10}$ Eq. (11) is an equality because managers leave no money on the table. The governance constraint is binding, not slack. Solving Eq. (11) for $d_{t}$ (see appendix) gives the following proposition:

Proposition 1 The threat of collective action forces payout to move together with the aftertax cost of managers' rents. If it would be optimal for shareholders to keep the firm alive then:

$$
h d_{t}=\left(\frac{\alpha}{1-\alpha}\right) r_{t}(1-\tau s) h
$$

If it would be optimal for shareholders to liquidate the firm then:

$$
h d_{t}=\left(\frac{\alpha}{1-\alpha}\right)\left\{r_{t}(1-\tau s) h+K_{t}\left[1-\beta E_{t}\left[\Pi_{t+h}\right](1-\tau)-\beta \tau\right]+(1-\tau) \Psi_{t}-\tau(1-\beta) D_{t}\right\}
$$

If it is optimal to keep the firm as a going concern, then payout to shareholders is proportional to the after-tax cost of rents. This is a tax-adjusted version of the governance constraint in Lambrecht and Myers (2012). A fraction $s$ of rents is tax-deductible, so corporate taxes relax the governance constraint and enable higher rents.

If shareholders would close the firm, then managers have to give shareholders extra payout to compensate for not exercising an abandonment put. The added compensation is a fraction for simplicity that shareholders, if they were to intervene, would just take $F_{t}$ or $N_{t}$, whichever is higher. An optimal exercise rule could shift the point at which the governance constraint based on liquidation value replaces the constraint based on going-concern value. Proposition 1 below correctly specifies the payout policy for each constraint, but it does not solve for the optimal switching point between the constraints. Integrating an optimal exercise rule in our framework would significantly complicate the analysis with few additional insights. Lambrecht and Myers (2008) derive the optimal payout switching point, but within a setting where debt and investment are held constant. The matter is, however, moot for what follows as switching between constraints does not arise in our worked out examples in sections 3 and 4.

${ }^{10} \mathrm{We}$ could also include a fixed cost of collective action $f$. The effect would be to reduce the payout in proposition 1 by a constant amount proportional to the interest on $f$. 
$\alpha /(1-\alpha)$ of the expected return shortfall on the capital $K_{t}$ invested, plus the after-tax cost $(1-\tau) \Psi_{t}$ minus the debt tax-shield.

Proposition 1 is valid regardless of managers' utility function and the profit process $\pi_{t}$. It reduces managers' decision problem by one control variable (by $d_{t}$ given $r_{t}$, for example) because the constraint Eq. (11) is binding at all times.

Managers do not leave money on the table by paying out more than is needed to keep outsiders at bay. Conversely, managers cannot cut payout relative to rents by promising extra payout later, because promises are not credible. Therefore, the governance constraint Eq. (11) does not rely on managers committing to keep future payout promises. We do assume that managers will act rationally - and entirely in their self interest - in each future period, and that shareholders anticipate the managers' decision rules. The managers will take the level of rents that is optimal for them, recognizing, however, that every dollar of rents has to be matched by $\alpha(1-\tau s) /(1-\alpha)$ dollars of payout in the going-concern case, and by a state-dependent payout amount when the firm should be shut down.

\subsection{Managers' optimization problem}

We can now state the managers' optimization problem. Managers choose the investment, debt, payout and rent policies $\left(K_{t}, D_{t}, d_{t}, r_{t}\right)$ that maximize their expected lifetime utility of rents:

$$
M_{t}=\max E_{t}\left[\sum_{j=0}^{\infty} \omega^{j} u\left(r_{t+j h}^{\nu}\right) h\right]
$$

subject to the budget constraint and no-Ponzi condition:

$$
\begin{aligned}
& h(1-\tau s) r_{t}+h d_{t}=D_{t}-D_{t-h}[\Gamma(1-\tau)+\tau]+K_{t-h}\left[\Pi_{t}(1-\tau)+\tau\right]-K_{t} \\
& \lim _{j \rightarrow \infty}[\Gamma(1-\tau)+\tau]^{-j h} D_{t+j h}=0
\end{aligned}
$$


The first-order conditions for $D_{t}$ and $K_{t}$ give the following Euler equations:

$$
\begin{gathered}
\frac{\partial M_{t}}{\partial D_{t}}=u^{\prime}\left(r_{t}^{\nu}\right) \nu r_{t}^{\nu-1} \frac{\partial r_{t}}{\partial D_{t}} h+\omega E_{t}\left[u^{\prime}\left(r_{t+h}^{\nu}\right) \nu r_{t+h}^{\nu-1} \frac{\partial r_{t+h}}{\partial D_{t}} h\right]=0 \\
\frac{\partial M_{t}}{\partial K_{t}}=u^{\prime}\left(r_{t}^{\nu}\right) \nu r_{t}^{\nu-1} \frac{\partial r_{t}}{\partial K_{t}} h+\omega E_{t}\left[u^{\prime}\left(r_{t+h}^{\nu}\right) \nu r_{t+h}^{\nu-1} \frac{\partial r_{t+h}}{\partial K_{t}} h\right]=0 \text { where : } \\
\frac{\partial r_{t}}{\partial D_{t}}=\frac{\left\{1-(1-\tau) \frac{\partial \Psi_{t}}{\partial D_{t}}-h \frac{\partial d_{t}}{\partial D_{t}}\right\}}{h\left[1-\tau s+\frac{\partial d_{t}}{\partial r_{t}}\right]} \text { and } \frac{\partial r_{t+h}}{\partial D_{t}}=\frac{(-1)\left\{\Gamma(1-\tau)+\tau+(1-\tau) \frac{\partial \Psi_{t+h}}{\partial D_{t}}+h \frac{\partial d_{t+h}}{\partial D_{t}}\right\}}{h\left[1-\tau s+\frac{\partial d_{t+h}}{\partial r_{t+h}}\right]} \\
\frac{\partial r_{t}}{\partial K_{t}}=\frac{\left\{-1-(1-\tau) \frac{\partial \Psi_{t}}{\partial K_{t}}-h \frac{\partial d_{t}}{\partial K_{t}}\right\}}{h\left[1-\tau s+\frac{\partial d_{t}}{\partial r_{t}}\right]} \text { and } \frac{\partial r_{t+h}}{\partial K_{t}}=\frac{\left\{\Pi_{t+h}(1-\tau)+\tau-(1-\tau) \frac{\partial \Psi_{t+h}}{\partial K_{t}}-h \frac{\partial d_{t+h}}{\partial K_{t}}\right\}}{h\left[1-\tau s+\frac{\partial d_{t+h}}{\partial r_{t+h}}\right]}
\end{gathered}
$$

Note how the marginal changes in current $\left(\frac{\partial r_{t}}{\partial D_{t}}, \frac{\partial r_{t}}{\partial K_{t}}\right)$ and future $\left(\frac{\partial r_{t+h}}{\partial D_{t}}, \frac{\partial r_{t+h}}{\partial K_{t}}\right)$ rents are multiplied by the marginal utilities of rents $u^{\prime}\left(r_{t}^{\nu}\right) \nu r_{t}^{\nu-1}$ and $u^{\prime}\left(r_{t+h}^{\nu}\right) \nu r_{t+h}^{\nu-1}$. With concave utility $\left(u^{\prime \prime}<0\right)$ and/or decreasing monetary returns from rent extraction $(\nu<1)$, satiation kicks in as managers receive more upfront rents at the expense of future rents. Therefore rents will be smoothed. Decreasing marginal utility will also limit both debt and investment as managers optimize period by period. Managers will underinvest, compared with the value-maximizing investment that shareholders would like them to make, and will limit borrowing. There is an interior optimal debt level, even if interest tax shields add market value and there are no frictions other than corporate taxes $\left(\Psi_{t}=0\right.$ and $\left.\nu=1\right)$.

An interior optimal debt ratio means that the managers will not exploit interest tax shields fully. Suppose that, having reached their optimum, they consider issuing $\$ 1$ million more of debt. They could pay out $\alpha$ million of the debt proceeds to shareholders, keep a bonus of $(1-\alpha) /(1-\tau s)$ for themselves and add market value from present and future interest tax shields. But the extra debt would reduce future payout and rents because of required debt service. (Debt is a senior claim, so managers' share of future debt service must come from rents. ${ }^{11}$ The one-off bonus would disrupt rent smoothing, increasing current rents at the expense of more efficient rent extraction in the future, leaving the managers worse off. Thus

\footnotetext{
${ }^{11}$ Managers can capture a fraction of the cash inflow from additional corporate borrowing, but the same
} 
at their optimum the managers have already maximized expected lifetime utility and any further capital structure changes could only decrease it.

Put it another way: Interest on debt accrues at the after-tax rate $\Gamma(1-\tau)+\tau \approx 1+\rho h(1-\tau)$. The managers' optimum debt policy adapts to this rate, not to the pre-tax rate used by shareholders. The Euler Eq. (17) relates managers' intertemporal marginal rate of substitution to the after-tax corporate borrowing rate. Assume for simplicity that $\Psi_{t}=0=\frac{\partial d_{t+h}}{\partial D_{t}}=\frac{\partial d_{t}}{\partial D_{t}}$. Define managers' stochastic discount factor as $w_{t+h} \equiv \omega u^{\prime}\left(r_{t+h}^{\nu}\right) \nu r_{t+h}^{\nu-1} /\left(u^{\prime}\left(r_{t}^{\nu}\right) \nu r_{t}^{\nu-1}\right)$. The Euler equation (17) becomes:

$$
1=[\Gamma(1-\tau)+\tau] E_{t}\left[w_{t+h}\right] \Longleftrightarrow E_{t}\left[w_{t+h}\right]=[\Gamma-\tau(\Gamma-1)]^{-1} \approx[1+\rho h(1-\tau)]^{-1}
$$

Hence, in equilibrium managers' effective discount rate equals the after-tax borrowing rate (ignoring the effect of adjustment costs $\Psi_{t}$ ). Suppose that managers issue one extra dollar of debt that will be repaid with interest at $t+h$. Eq. (19) implies that the managers see the NPV of this debt issue as zero 12

$$
E\left[w_{t+h}\right]=[\Gamma-\tau(\Gamma-1)]^{-1} \Longleftrightarrow N P V=1-E\left[w_{t+h}\right][\Gamma-\tau(\Gamma-1)]=0
$$

Yet the NPV of a marginal dollar of debt to shareholders equals $N P V=1-\beta[\Gamma-\tau(\Gamma-1)]=$ $\tau(1-\beta)>0$, which is the standard interest tax shield.

The same reasoning works in reverse. Suppose tax shields are small and overmatched by costs of debt (by way of $\Psi_{t}>0$ ). Would the managers issue equity in order to pay down $\$ 1$ million of debt? Not if the transaction started from the managers' optimal path of rents. The managers could issue $\alpha$ million of equity (or cut payout by $\alpha$ million) but would have to put fraction of debt service comes out of managers' future rents. (The fraction depends on how tight the governance constraint is.) Thus a fraction of corporate debt amounts to borrowing on behalf of managers. Also managers must co-invest when the firm's capital stock expands, either by cutting back rents or by allocating their share of additional borrowing to finance their share of investment. See Myers (2000) and Lambrecht and Myers (2012) for a fuller discussions of corporate borrowing and co-investment.

${ }^{12}$ We thank one of the referees for pointing this out. 
up $(1-\alpha) /(1-\tau s)$ in the form of lower current rents ${ }^{13}$ The managers could then increase future rents, but the net effect, starting from their optimum, would decrease expected lifetime utility.

These comments clarify how debt disciplines managers, even when there are no costs or restrictions on the amount of cash raised by debt or equity issues $\left(\Psi_{t}=0\right)$. An increase in the current level of debt reduces the future rents that the managers will extract, which in turn leads managers to reduce immediate rents in order to moderate the reduction in future rents. The discipline therefore comes from the effects of corporate borrowing on managers' optimal dynamic path of rents, which is smoothed. It is self-discipline, not discipline imposed by costs or frictions in raising the cash required for immediate debt service.

Compare the expressions for $h \frac{\partial r_{t+j h}}{\partial D_{t}}$ and $h \frac{\partial r_{t+j h}}{\partial K_{t}}($ for $j=0,1)$ with the expressions between square brackets in Eqs. (8) and (9). Assume the firm is worth more as a going concern. The comparison shows that the marginal dollar increases due to a change in debt or investment are the same as in the risk-neutral case up to a scaling factor $1 /\left(1-\tau s+\frac{\partial d_{t+j h}}{\partial r_{t+j h}}\right)=(1-$ $\alpha) /(1-\tau s)\left(\right.$ with $\frac{\partial d_{t+j h}}{\partial D_{t}}=\frac{\partial d_{t+j h}}{\partial K_{t}}=0$ for $\left.j=0,1\right)$. The scaling factor is determined by the tax deductibility of managers' rents (payouts to the investors are not tax deductible) and by the degree of investor protection $\alpha$. The governance constraint requires that managers get the fraction $(1-\alpha) /(1-\tau s)$ of each dollar of additional borrowing, with shareholders getting the remaining fraction. A dollar more paid for debt service reduces rents by $(1-\alpha) /(1-\tau s)$ dollars. Thus the marginal utility of a dollar of debt or debt service equals $(1-\alpha) /(1-\tau s)$ times the marginal utility of rent extraction.

The expressions for $h \frac{\partial r_{t+j h}}{\partial D_{t}}$ and $h \frac{\partial r_{t+j h}}{\partial K_{t}}$ (for $\left.j=0,1\right)$ are different for the regime in which investors would close the firm, because in that case $\frac{\partial d_{t+j h}}{\partial D_{t}} \neq 0$ and $\frac{\partial d_{t+j h}}{\partial K_{t}} \neq 0$ for $j=0,1$. The level of debt and capital stock now has a direct effect on current payout to shareholders

\footnotetext{
13 There are no information problems or other frictions in our model that would deter equity issues. The managers abstain in this example because it is not in their interest to issue equity.
} 
and also an effect on next period's payout if there are adjustment costs $\left(\partial \Psi_{t+h} / \partial D_{t} \neq 0\right.$ or $\left.\partial \Psi_{t+h} / \partial K_{t} \neq 0\right)$. We discuss this in detail in the next section where we have explicit expressions for $r_{t}$ in each regime.

We conclude this section by examining the effect of the governance constraint on managers' rents. Let $R_{t}$ denote the market value of rents, $R_{t}=E_{t}\left[\sum_{j=0}^{\infty} \beta^{j} h r_{t+j h}\right]$. The budget constraint Eq. (15) and Eq. (6) require that:

$$
R_{t}+S_{t}=V_{t}-(\Gamma(1-\tau)+\tau) D_{t-h}+T_{t}+\tau s R_{t} \equiv F_{t}+\tau s R_{t}
$$

In addition to a debt taxshield $T_{t}$, the firm also has a rent tax shield $\tau s R_{t}$. Shareholders cannot recoup the rent tax shield if they intervene, because intervention eliminates rents, as is clear from the governance constraint Eq. (11).

The effects of corporate taxes on rents and stock market value may be positive or negative. Higher taxes reduce shareholders' going concern value, $F_{t}$, but also create a rent tax shield that allows managers to lever up rents by a factor $1 /(1-\tau s)$. The latter effect may dominate for high tax rates. We return to these issues in more detail in the next section.

Rearranging Eq. (21) and substituting $S_{t}$ by the governance constraint gives:

$$
R_{t}=\min \left[\frac{(1-\alpha) F_{t}}{1-\tau s}, \frac{F_{t}-\alpha N_{t}}{1-\tau s}\right]
$$

The first and second argument of the min operator give the market value of managers' rents if shareholders would operate $\left(F_{t} \geq N_{t}\right)$ or liquidate $\left(F_{t}<N_{t}\right)$ the firm. The cost of collective action $(\alpha<1)$ creates space for managers to continue the firm when it ought to be closed down $\left(N_{t}>F_{t}>\alpha N_{t}\right)$, but managers' rents are squeezed as the going concern value drops further below liquidation value. Managers wait too long to close the firm but have to sacrifice rents for doing so.

We now move to a closed-form version of the general model. 


\section{A closed form solution}

To solve the model explicitly we need to specify the utility $(u)$ and cost $\left(\Psi_{t}\right)$ functions, the time increment $(h)$ and the stochastic process $\left(\pi_{t}\right)$ that generates the return on investment. We assume in this section that managers have power utility (constant relative risk aversion or CRRA), with $u\left(r^{\nu}\right)=\frac{\left(r^{\nu}\right)^{1-\eta}}{1-\eta} \equiv \frac{\nu r^{\gamma}}{\gamma}$, where $0<\eta($ and $\eta \neq 1$ ) and $0<\nu<1$ and $\gamma \equiv(1-\eta) \nu 14$ The return on risky assets, $\pi_{t}$, is given by the following process:

$$
\pi_{t} h=\left(\mu-\frac{\sigma^{2}}{2}\right) h+\sigma \epsilon_{t} \sqrt{h} \text { where } \epsilon_{t} \sim \text { i.i.d. } N(0,1)
$$

where $\mu$ is defined net of capital depreciation but before production costs are subtracted. Hence $\pi_{t}$ follows a diffusion process in continuous time as $h \rightarrow 0$. Investment opportunities, which are defined by $\mu$ and $\sigma$, are assumed known and constant.

We assume that $\Psi_{t}$ represents the firm's production cost, with $\Psi_{t} \equiv h \phi K_{t}\left(\frac{K_{t}}{N_{t}}\right)^{\theta-1}$. We assume $\theta>1$, so that the instantaneous net return on capital decreases with investment (decreasing instantaneous returns to scale). This cost function is required in order to have a bounded investment policy for the first-best, risk-neutral benchmark. The cost function is not essential for managers' optimization problem. ${ }^{15}$

To solve the problem in continuous time, we first derive the continuous-time equivalent of the governance constraints in proposition 1. Taking the continuous-time limit $h \rightarrow 0$ by using L'Hôpital's rule gives the following proposition:

Proposition 2 The continuous-time version of the governance constraint is as follows. If it

\footnotetext{
${ }^{14}$ The limiting case $\eta=1$ corresponds to $\log$ utility. The plots in Figures 1 and 2 below show that the solution is numerically well behaved in the neighborhood of $\eta=1$, so we do not present analytical solutions for this limiting case.

${ }^{15}$ We assume that the firm can buy or sell the risky assets $K$ and issue or retire debt with no frictions or adjustment costs. We comment on adjustment costs below.
} 
would be optimal for shareholders to keep the firm alive then

$$
d_{t}=\left(\frac{\alpha}{1-\alpha}\right) r_{t}(1-\tau s) \equiv \alpha m r_{t} \text { where } m \equiv \frac{1-\tau s}{1-\alpha}
$$

If it would be optimal for shareholders to liquidate the firm then

$$
d_{t}=\left(\frac{\alpha}{1-\alpha}\right)\left\{r_{t}(1-\tau s)+K_{t}(\rho-\mu(1-\tau))-\rho \tau D_{t}+(1-\tau) \phi K_{t}\left(\frac{K_{t}}{N_{t}}\right)^{\theta-1}\right\}
$$

The key state variable for managers' optimization problem is the firm's net worth worth, $N_{t}$, which includes accumulated retained earnings. The budget constraint Eq. (3) implies:

$$
\begin{aligned}
N_{t+h}-N_{t}= & K_{t}\left[e^{\pi_{t+h} h}(1-\tau)+\tau-1\right]-D_{t}\left[e^{\rho h}(1-\tau)+\tau-1\right] \\
& -h r_{t}(1-\tau s)-h d_{t}-h(1-\tau) \phi K_{t}\left(\frac{K_{t}}{N_{t}}\right)^{\theta-1}
\end{aligned}
$$

By using L'Hôpital's rule the continuous-time limit $(h \rightarrow 0)$ can be expressed as a stochastic differential equation. Also in continuous time the budget constraint Eq. (3) implies that $D_{t}=K_{t}-N_{t}$. The process for net worth is therefore:

$$
d N_{t}=\left[\left(\mu^{*}-\rho^{*}-\phi^{*}\left(\frac{K_{t}}{N_{t}}\right)^{\theta-1}\right) K_{t}+\rho^{*} N_{t}-(1-\tau s) r_{t}-d_{t}\right] d t+\sigma^{*} K_{t} d z
$$

where $\mu^{*} \equiv \mu(1-\tau), \rho^{*} \equiv \rho(1-\tau), \sigma^{*} \equiv \sigma(1-\tau), \phi^{*} \equiv \phi(1-\tau)$, and $d z$ is a Wiener process.

Payout and rents act as a drain on the growth of net worth $N_{t}$. Once investment $\left(K_{t}\right)$ and total payout $\left(r_{t}\right.$ plus $\left.d_{t}\right)$ are set, net debt $\left(D_{t}\right)$ follows from the budget constraint. Three different regimes are possible for the net worth process $N_{t}$ (described by Eq. (27)), depending on which of the governance constraints determines payout $\left(d_{t}\right)$ and rents $\left(r_{t}\right)$. The regimes correspond to the case where shareholders would keep the firm as a going concern (regime i $=1$, with $F_{t}>N_{t}$ ), close it down (regime i $=3$, with $F_{t}<N_{t}$ ) or be indifferent between continuation and closure (regime $\mathrm{i}=2$, with $F_{t}=N_{t}$ ).

In the going-concern regime 1 , where $S_{t}=\alpha F_{t}$ and therefore $R_{t}=F_{t} / m, d_{t}$ and $r_{t}$ move in lockstep according to Eq. (24). In the liquidation regime 3, where $S_{t}=\alpha N_{t}$ and $R_{t}=\left(F_{t}-\alpha N_{t}\right) /(1-\tau s)<N_{t} / m, d_{t}$ and $r_{t}$ move in lockstep according to Eq. 25). 
It is also possible that both the going-concern and the liquidation constraint bind simultaneously $\left(S_{t}=\alpha N_{t}\right.$ and $\left.R_{t}=N_{t} / m\right)$ and that $F_{t}=N_{t}$ so that shareholders would not care whether the firm continues or is liquidated. Payout still moves in lockstep with rents according to Eq. (24) but managers set $K_{t}$ at a level such that $F_{t}=N_{t}$. Managers' investment policy $K_{t}$ in this regime is the solution to:

$$
K_{t}(\rho-\mu(1-\tau))-\rho \tau D_{t}+(1-\tau) \phi K_{t}\left(\frac{K_{t}}{N_{t}}\right)^{\theta-1}=0
$$

We can now formulate managers' optimization problem. They set rents $r_{t}$ and investment $K_{t}$ to optimize:

$$
M\left(N_{0}\right)=\max _{r_{t}, K_{t}} E_{0}\left[\int_{0}^{\infty} e^{-\delta t} \frac{\nu r_{t}^{\gamma}}{\gamma} d t\right]
$$

subject to the transversality condition $\lim _{t \rightarrow \infty} E\left[e^{-\delta t} M\left(N_{t}\right)\right]=0$ and the intertemporal budget constraint Eq. (27), which incorporates according to the prevailing regime the relevant governance constraint given in proposition 2. The transversality condition ensures that the integral converges. This optimization problem is closely related to the well-known portfolioconsumption problem (see the seminal papers by Merton $(1969,1971)$ ). The solution (see appendix for the derivation) is:

Proposition 3 The optimal investment policy $\left(K_{i t}\right)$, rent policy $\left(r_{i t}\right)$, debt policy $\left(D_{i t}\right)$ and managers' lifetime utility $\left(M_{i t}\right)$ for regime $i$ are:

$$
\begin{array}{ll}
k_{i}\left[\mu-\rho-\phi \theta\left(\frac{K_{i t}}{N_{t}}\right)^{\theta-1}\right]=(1-\gamma){\sigma^{*}}^{2}\left(\frac{K_{i t}}{N_{t}}\right) & \text { for } i=1,3 \\
\left(\frac{K_{2 t}}{N_{t}}\right)(1-\tau)\left[\mu-\rho-\phi\left(\frac{K_{2 t}}{N_{t}}\right)^{\theta-1}\right]=\rho \tau & \text { for } i=2 \\
r_{i t}=\left(\frac{m b_{i}}{\nu}\right)^{\frac{1}{\gamma-1}} N_{t} \equiv q_{i} N_{t} & \text { for } i=1,2,3 \\
D_{i t}=\left(l_{i}-1\right) N_{t} & \text { for } i=1,2,3 \\
M_{i t}=b_{i} \frac{N_{t}^{\gamma}}{\gamma} & \text { for } i=1,2,3
\end{array}
$$


The constant $b_{i}$ is the solution to:

$m\left(\frac{m b_{i}}{\nu}\right)^{\frac{1}{\gamma-1}} \frac{(1-\gamma)}{\gamma}+\rho n_{i}-\frac{\delta}{\gamma}+k_{i}\left(\mu-\rho-\phi l_{i}{ }^{\theta-1}\right) l_{i}+\frac{1}{2} \sigma^{* 2}(\gamma-1) l_{i}{ }^{2}=0$ for $i=1,2,3$

where $l_{i}=l_{i t} \equiv \frac{K_{i t}}{N_{t}}$ and $l_{i}$ is the solution to (30) for $i=1,3$ and to (31) for $i=2$, and where $k_{1} \equiv 1-\tau, k_{2} \equiv 0, k_{3} \equiv \frac{1-\tau}{1-\alpha}, n_{1} \equiv 1-\tau, n_{2} \equiv 1$, and $n_{3} \equiv \frac{1-\alpha-\tau}{1-\alpha}$. The regime under which managers operate does not depend on the level of the state variable $N_{t}$, and regime switching therefore does not occur.

The firm's financial policies depend on whether it is worth strictly more alive than dead and therefore on whether it has high or low after-tax profits. Profitability depends on several parameters, but not on the level of the state variable $N_{t}$. Since $F_{t}$ is proportional to $N_{t}$ (see corollary 1), the ratio $F_{t} / N_{t}$ must be constant.

The firm never switches regime when expected profitability is constant. As $N_{t}$ drops, the firm shrinks and becomes a miniature, but otherwise identical, version of its previous self. If the firm's fortunes deteriorate and $N_{t}$ falls, then investment, debt, payout and rents all shrink proportionally, since $K_{t}=l_{i} N_{t}, r_{t}=q_{i t} N_{t}$ and $D_{t}=\left(l_{i}-1\right) N_{t}$.

There are critical profitability rates $\hat{\mu}$ and $\bar{\mu}(\hat{\mu}>\bar{\mu})$ that determine the three possible regimes. Since the going concern value $F_{t}$ is increasing in $\mu$, these rates are the solutions to $F_{1 t}\left(N_{t} ; \hat{\mu}\right)=N_{t}$ and $F_{3 t}\left(N_{t} ; \bar{\mu}\right)=N_{t}$, or equivalently (see proof to proposition 3 ):

$$
\rho \tau=(1-\tau)\left[(\hat{\mu}-\rho) l_{1}-\phi l_{1}^{\theta}\right] \text { and } \rho \tau=(1-\tau)\left[(\bar{\mu}-\rho) l_{3}-\phi l_{3}^{\theta}\right]
$$

Regime 1 (3) corresponds with high (low) profitability rates. Of course, the profitability rate is not the only parameter that could determine the three regimes. If we fix $\mu$ but vary the tax rate $\tau$ then $(36)$ could be solved for $\hat{\tau}$ and $\bar{\tau}$. The same three regimes would occur, with regime 1 (3) coinciding with low (high) tax rates.

Managers' investment policy deviates from what shareholders would do if they were in 
charge. One can show (see online appendix A) that there exists a critical profitability rate $\mu^{o}$ such that shareholders adopt the first-best investment policy, $l^{\circ}$ (which can be obtained by setting $\gamma=1$ in Eq. (30) for $\mu \geq \mu^{o}$ and shareholders close the firm for $\mu<\mu^{o}$. Furthermore, $\mu^{o}<\bar{\mu}$, which means that the first-best closure region corresponds to profitability rates that are sufficiently low and within regime 3 . Inefficiently late closure by managers therefore only occurs in regime 3 , and this for a range of sufficiently low profitability rates.

Shareholders would only want to finance the firm in the first place if $\mu>\mu^{o}$. However, a firm could start, say, in regime 1 but end up in another because of some unanticipated change, for example a hike in the tax rate or a drop in expected profitability.

We will focus on regimes 1 and 3, which include most of our model's economic insights. A more detailed discussion of regime 2 is in online appendix C.

\subsection{Investment}

The optimal investment policy implies a constant ratio of capital to net worth, with $l_{i}=$ $K_{i t} / N_{t}$. The first-order conditions that pin down $l_{i}$ for regime 1 and 3 (see equation (30)) only differ by a constant factor $k_{i}$, where $k_{1}=1-\tau$ and $k_{3}=(1-\tau) /(1-\alpha)$. Therefore investment is higher relative to net worth in regime 3 than in regime 1 , for the same profitability rate $\mu$ and production-cost function $\Psi$. (Of course the firm can only be in one particular regime for given values of $\mu$ and $\Psi$.) In regime 1 , managers are in effect co-owners of the firm, splitting going concern value $F_{t}$ with shareholders. The shareholders get the fraction $\alpha$ and managers $1-\alpha$. But in regime 3, where the shareholders would close the firm down, the shareholders have a fixed claim worth $\alpha N_{t}$. The managers become the only residual claimants and so have an incentive to invest more.

Equation (30) reveals how managers' CAPEX decison depends on the parameters $\sigma$ and $\gamma$ in regimes 1 and 3 . Recall that $\gamma \equiv(1-\eta) \nu$ acts as a modified coefficient of risk aversion that 
also depends on the increasing marginal cost of rent extraction $(\nu)$. Higher return volatility $(\sigma)$ or risk aversion $(\eta>0)$ and decreasing returns to rent extraction $(\nu<1)$ reduce investment. Since $\nu$ affects investment only through $\gamma$ (see equation (30p) decreasing returns from rent extraction has the same effect on investment as increasing risk aversion.

Managers' personal rate of time preference $\delta$ does not affect investment ${ }^{16}$ CAPEX increases with the expected return on risky capital $(\mu)$ and decreases with the safe rate of interest $(\rho){ }^{17}$ CAPEX always falls short of its first best value-maximizing level.

Taxes reduce the after-tax return, but (assuming losses are tax deductible) also reduce volatility $\left(\sigma^{*} \equiv \sigma(1-\tau)\right)$. Lower returns decrease investment whereas lower volatility increases investment. The reduced volatility dominates: A higher tax rate reduces the risk borne by managers, so the net effect of taxes on investment is positive ${ }^{18}$

\subsection{Payout and rents}

Optimal rents are a linear function of the firm's net worth, with $r_{i t}=q_{i} N_{t}$ for all regimes. The governance constraint determines payout to shareholders as $d_{1 t}=\alpha m q_{1} N_{t}$ in regime 1 , where the firm is valued solely as a going concern. In regimes 2 and 3 , where going-concern value is less than or equal to liquidation value, $d_{i t}=\alpha\left(\rho-g_{i}\right) N_{t}$, where $g_{i}$ is the drift of the

\footnotetext{
${ }^{16}$ The first order condition for investment, as given by equation $(59)$, depends on the derivatives $M^{\prime}(N)$ and $M^{\prime \prime}(N)$ which in turn depend on managers' time preference rate $\delta$ through the constant $b$. While the constant $b$ can be factored out with power utility (and negative exponential utility see below), this may not be true in general.

${ }^{17}$ But CAPEX actually decreases with $\mu$ in regime 2 . Higher profitability decreases the amount of CAPEX needed to keep the going-concern governance constraint binding. See online appendix $\mathrm{C}$ for further details.

${ }^{18}$ Substitute $k_{1} \equiv 1-\tau$ or $k_{3} \equiv \frac{1-\tau}{1-\alpha}$ and $\sigma^{* 2} \equiv \sigma^{2}(1-\tau)^{2}$ in Eq. $\sqrt{30}$. Divide through by $1-\tau$. The only net effect of taxes is to reduce $\sigma^{2}$ by the factor $1-\tau$. Lower risk means more investment.
} 
net worth process $N_{t}$, with:

$$
\begin{aligned}
d N & =\left[k_{i}\left(\mu-\rho-\phi l_{i}^{\theta-1}\right) l_{i}+\rho n_{i}-m q_{i}\right] N d t+\sigma^{*} l_{i} N d z \text { for } i=1,2,3 \\
& \equiv g_{i} N d t+\sigma_{i N} N d z \text { for } i=1,2,3
\end{aligned}
$$

Thus $N_{t}$ follows a geometric Brownian motion and takes on positive values only. The absence of jumps in $N_{t}$ combined with power utility (and therefore $u^{\prime}(0)=+\infty$ ) guarantees that rents and payout remain positive and debt is risk-free $\left(N_{t}=K_{t}-D_{t}>0\right)$.

Rents and payout are smoothed, because they depend on the firm's cumulative retained income $N_{t}$, rather than current income.

We can now calculate the market value of the managers' rents and shareholders' equity. The market values are $R_{t}=E_{t}\left[\int_{t}^{\infty} e^{-\rho y} r_{y} d y\right]$ and $S_{t}=E_{t}\left[\int_{t}^{\infty} e^{-\rho y} d_{y} d y\right]$. Since $N_{t}$ follows a geometric Brownian motion, the integrals are well known.

Corollary 1 Debt is risk-free with market value $D_{i t}=\left(l_{i}-1\right) N_{t}$. The market value of managers' rents $\left(R_{i t}\right)$, shareholders' equity $\left(S_{i t}\right)$ and total value to managers as well as shareholders $\left(F_{i t}=S_{i t}+(1-\tau s) R_{i t}\right)$ are:

$$
\begin{aligned}
& R_{1 t}=\frac{q_{1} N_{t}}{\rho-g_{1}}>\frac{(1-\alpha) N_{t}}{1-\tau s} \quad R_{2 t}=\frac{q_{2} N_{t}}{\rho-g_{2}}=\frac{(1-\alpha) N_{t}}{1-\tau s} \quad R_{3 t}=\frac{q_{3} N_{t}}{\rho-g_{3}}<\frac{(1-\alpha) N_{t}}{1-\tau s} \\
& S_{1 t}=\frac{\alpha m q_{1} N_{t}}{\rho-g_{1}} \quad S_{2 t}=\alpha N_{t} \quad S_{3 t}=\alpha N_{t} \\
& F_{i t}>N_{t} \quad F_{2 t}=N_{t} \quad F_{3 t}<N_{t}
\end{aligned}
$$

The growth condition $\rho>g_{i}$ ensures that market values are positive and bounded.

In regime 1 , going-concern value exceeds liquidation value $\left(F_{t}>N_{t}\right)$, and the values of shareholders' equity and rents depend on total going-concern value. Shareholders' total goingconcern value, $F_{t}$, captures the expected present value of the firm's future net income, but excluding the rent tax shield.

In regime 2, managers increase investment to ensure that the going concern value equals 
the liquidation value $\left(F_{t}=N_{t}\right)$. Shareholders have no incentive to intervene $\left(S_{2 t}=\alpha N_{t}\right) . R_{2 t}$ exceeds $(1-\alpha) N_{t}$ because managers benefit from the rent tax shield.

In regime 3 , the firm is worth more dead than alive from shareholders' point of view $\left(F_{t}<\right.$ $\left.N_{t}\right)$. To prevent the firm from being closed, managers sacrifice enough of their rents to keep shareholders at bay. While this causes managers' claim $R_{3 t}$ to drop below $(1-\alpha) N_{t} /(1-\tau s)$, this does not mean that $R_{t}$ itself decreases, because higher taxes boost the rent tax shield, $\tau s R_{t}$, which loosens the governance constraint (recall from the governance constraint that rents are scaled by a factor $1 /(1-\tau s))$. This positive effect on managers' rents can outweigh the negative effect that corporate taxes have on profits 19 Corollary 1 allows us to calculate the rent and payout yield.

Corollary 2 The payout and rent yields are constant over time, with:

$$
\frac{d_{i t}}{S_{i t}}=\frac{r_{i t}}{R_{i t}}=\rho-g_{i}
$$

Payout and rents are a constant fraction $\rho-g_{i}$ of the market values of equity $\left(S_{t}\right)$ and rents $\left(R_{t}\right)$. Equity value is determined by the firm's continuation value $F_{t}$ in regime 1 and its liquidation value (net worth) $N_{t}$ in regimes 2 and 3 . Rents are a residual claim and therefore depend on $F_{t}$ in all three regimes. Since $F_{t}$ is determined by the present value of current and future net income, rents can be said to depend on the firm's permanent income. While permanent income is determined by current and future income, it is indirectly also based on past retained income. The firm's current income is a function of its net worth $N_{t}=K_{t}-D_{t}$, which in turn is determined by the firm's past retained earnings. Thus $N_{t}$ could be viewed as a payout reservoir. For example, John and Kalay (1982) report that many firms have debt covenants that link dividends to cumulative retained earnings, forbidding firms to pay out income not yet earned.

\footnotetext{
${ }^{19}$ These relationships appear in Figure 1 of the online appendix D.
} 
Managers could choose to deplete this reservoir all at once by liquidating the firm's capital stock and paying out what is left after paying off the debt $D_{t}$. This is what shareholders would do when $F_{t}<N_{t}$ if they were in charge. But managers distribute payout as a continuous flow instead. Thus payout and rents are a constant drain on the reservoir of retained earnings. Since payout and rents are linked to cumulative retained income (a stock variable) and not current income (a flow variable), payout and rents are smooth relative to the firm's net income.

Rents depend on the various model parameters through the constant $b_{i}$. Note, for example, that (unlike investment policy) rent and payout policies depend on managers' personal rate of time preference $\delta$. A higher $\delta$ makes managers more impatient and increases rents.

\subsection{Debt policy}

The firm's net debt level is a linear function of its net worth, with $D_{t}=\left(l_{i}-1\right) N_{t}$. The optimal net debt level is negative if $l_{i}<1$, which may happen for low tax rates, high levels of risk aversion and high investment return volatility (see Figure 2 in section 3.4 below). A firm with negative debt has more cash than debt. It is equivalent to an all-equity financed firm that has invested an amount $K_{t}$ in risky projects and an amount $N_{t}-K_{t}=\left(1-l_{i}\right) N_{t}>0$ in cash. As the firm's fortunes improve, the firm increases the dollar amount of cash it holds and its stock of risky investments. If $l_{i}>1$ then the firm has a positive amount of debt. This happens for higher tax rates (see Figure 2 below). Thus higher tax rates do increase corporate borrowing, even though managers do not exploit interest tax shields fully. An increase in the firm's net worth raises the firm's amount of debt and its stock of capital.

We can now calculate the firm's leverage under the optimal investment and payout policy. With negative debt the traditional leverage ratio is hard to interpret. Lambrecht and Pawlina (2013) provide an economic rationale for using the net debt ratio (NDR) as defined below:

Corollary 3 Define the firm's net debt ratio as $N D R_{t} \equiv \frac{D_{t}}{S_{t}+R_{t}+I D_{t}}$ where $I=1$ if $D_{t} \geq 0$ 
and $I=0$ if $D_{t}<0$. The NDR is constant over time and given by:

$N D R_{i t}=\frac{\left(l_{i}-1\right)}{P_{i}+I\left(l_{i}-1\right)}$ where $P_{1} \equiv \frac{\alpha m q_{1}+q_{1}}{\rho-g_{1}}, P_{2} \equiv \alpha+\frac{1-\alpha}{1-\tau s}$ and $P_{3} \equiv \alpha+\frac{q_{3}}{\rho-g_{3}}$

The firm has an optimal target net debt ratio, similar to the leverage target predicted by the tradeoff theory of capital structure. However, in the presence of taxes and the absence of bankruptcy costs the standard tradeoff theory of capital structure predicts $100 \%$ debt financing. Our model predicts a significantly lower leverage level because of managers' desire to smooth rents. Higher managerial risk aversion and lower corporate taxes lead to a lower NDR. (See Figure 2 below.)

With power utility, decisions about debt, rents, payout and CAPEX cannot be separated; none is independent of the others. The firm responds to positive demand shocks by financing increased CAPEX with a combination of additional borrowing and retained earnings. It responds to negative shocks by selling off assets and paying down debt. Payout and rents respond to demand shocks, but slowly, because they depend on cumulative income, not current income.

\subsection{Examples}

Figures 1 and 2 illustrate how going-concern value, CAPEX, rents (and therefore payout) and capital structure depend on profitablity, risk aversion and the tax rate. We plot results for two different levels of volatility $(\sigma)$.

Panel A of Figure 1 shows that the ratio of going-concern value to net worth increases with $\mu$, the expected rate of return on CAPEX. The ratio is less than 1.0 in the low-profit regime 3 (on the left). The ratio equals 1.0 exactly in regime 2 (between $\mu=0.108$ and 0.112 for $\sigma=0.2$ ), where both the going-concern and liquidation constraints are binding. As $\mu$ increases in the high-profit regime 1 , the growth rate $g$ of net worth rises and value increases rapidly ${ }^{20}$

\footnotetext{
${ }^{20}$ Value explodes as the growth rate $g$ of net worth approaches the cost of capital $\rho$. The explosion is a
} 
Raising volatility from 0.2 (solid line) to 0.4 (dashed line) decreases the going concern value.

Panel B plots the optimal ratio of the capital stock to net worth. The expected return $\mu$ must exceed $\rho$ for managers to invest at all. The capital to net worth ratio increases rapidly as $\mu$ moves above about 0.08 . But the ratio declines with $\mu$ in the intermediate regime 2 where the capital to net worth ratio is determined entirely by the governance constraint. Growth of the ratio resumes in the high-profitability regime 3 . Increasing the volatility of the return on investment from $\sigma=0.2$ (solid line) to $\sigma=0.4$ (dashed line) reduces the stock of capital.

Panel $\mathrm{C}$ shows that the ratio of rents to net worth declines with expected profitability. As $\mu$ increases, the firm's growth rate $g$ increases and managers prefer to sacrifice current rents in favor of future growth. But the levels of rents and payout increase as net worth grows. Higher volatility reduces the growth rate and increases the ratio of rents to net worth.

The optimal NDR (panel D) increases with the expected profitability in regimes 1 and 3. For sufficiently low $\mu, \mathrm{CAPEX}=0\left(l_{3}=0\right)$ and the firm keeps all its net worth in cash. This explains why the NDR drops to -1.0 as $\mu$ decreases towards $\rho$. As $\mu$ rises further above $\rho$, the firm invests some of its net worth in its capital stock and the remainder in cash. Once the NDR exceeds 0 , the firm invests all its net worth plus borrowing in its capital stock. Comparing plots $\mathrm{B}$ and $\mathrm{D}$ shows that investment and financing move in tandem: a higher capital to net worth ratio corresponds to a higher NDR. The NDR falls in the intermediate regime 2 exactly in sync with the fall in the capital stock.

Panels $\mathrm{A}$ and $\mathrm{C}$ in Figure 2 illustrate the effects of corporate taxes. Panel A plots the optimal capital to net worth ratio, which increases monotonically with the tax rate. (Recall that the net effect of taxes is higher CAPEX, because higher taxes reduce the risk borne by managers.) The solution converges to the first-best investment level (relative to net worth) feature of all valuation models with cash flows growing at a constant expected rate. Our solution requires $g<\rho$. 
$l^{\circ}=6.55$ as $\tau \rightarrow 1$ and therefore $\sigma^{*} \rightarrow 0$. Managers' optimal levels of capital stock are less than half their first-best levels for plausible tax rates, however. A more volatile return on investment (higher $\sigma$ ) reduces investment.

The optimal NDR (panel C) increases with the corporate tax rate due to a higher capital to net worth ratio and the tax deductibility of interest. Higher volatility reduces leverage. For $\sigma=0.4$, the NDR is negative for corporate tax rates up 35\%. For tax rate rates below $20 \%$ the NDR is about -0.4 , indicating that $40 \%$ of the firm's (all-equity financed) assets are invested in cash, and the remainder in risky assets.

Panels B and D illustrate the effects of managers' coefficient of risk aversion $\eta$ on managers' investment and financing policies, respectively. Recall that $\eta=0$ means risk neutrality; higher values for $\eta$ imply higher risk aversion ${ }^{21}$ The figure confirms that the optimal capital to net worth ratio and the NDR decrease with $\eta$. Both the investment and financing policies are independent of risk aversion in regime two, where policies are determined by risk-neutral shareholders' governance constraint. (Regime 2 arises for $1.081<\eta<3.1$ if $\sigma=0.2$ and for $0.085<\eta<13.1$ if $\sigma=0.4$.) Our model generates a low or even negative NDR for a wide range of the risk-aversion coefficient.

The returns to scale on rent extraction, $\nu$, affects investment and capital structure through $\gamma$. Reducing $\nu$ has a similar effect as increasing the coefficient of risk aversion, $\eta$. If we fix $\eta=0.2$ and put $1-\nu$ on the $\mathrm{X}$-axis (with $\nu \in[0,1]$ ), then plots $\mathrm{B}$ and $\mathrm{D}$ in Figure 2 would remain the same for the parameter range $\nu \in[0,1]$. Of course, the plots would be right truncated, since $\nu$ takes on a narrower range of values than $\eta$.

\footnotetext{
${ }^{21}$ The first best investment policy is not achieved for $\eta=0$ if there are decreasing returns to rent extraction $(\nu=0.8<1)$. First-best investment requires $\gamma=(1-\eta) \nu=1$.
} 


\subsection{Adjustment costs}

We now briefly consider how adjustment costs could affect debt and investment policies. Online appendix B contains further details.

With power utility the optimal policy implies that, in the absence of adjustment costs, the ratio of net debt to risky capital is kept at a constant target level through constant rebalancing $\left(y_{t} \equiv D_{t} / K_{t}=(l-1) / l\right)$. Suppose now that the firm incurs proportional adjustment costs when adjusting its capital stock and when borrowing or paying down debt. Keeping $y_{t}$ constant is clearly no longer optimal: adjustment costs would explode as the firm tried to follow fluctuations of investment returns in continuous time. Constantinides (1986) and Davis and Norman (1990), among others, show that for portfolio-investment problems with proportional transaction costs, it is optimal to keep the ratio $y_{t}$ within an interval $[\underline{y}, \bar{y}]$. As long as $y_{t}$ is within this interval, managers would not intervene and would let $D_{t}$ and $K_{t}$ freely fluctuate. When $y_{t}$ hits $\bar{y}$, managers would sell risky assets and use the net proceeds to pay down debt. When $y_{t}$ hits $\underline{y}$, managers would borrow and expand investment. Managers' value function $M\left(D_{t}, K_{t}\right)$ is homogenous in $D$ and $K$ and therefore $M\left(D_{t}, K_{t}\right)=K_{t}^{\gamma} J\left(y_{t}\right)$. The optimal rent policy is the solution to the first order condition $\nu r_{t}^{\gamma-1}=-m M_{D}$.

The location of the range for the debt ratio depends on the same parameters that determine the target debt ratio with no adjustment costs. For example, the range shifts up for higher tax rates and down for increased risk aversion.

Shreve and Soner (1994) analyze the portfolio-consumption problem with proportional transaction costs and power utility. They show that, regardless of the model parameters, the proportion of net worth (wealth) held in the risky asset in the optimal portfolio remains in an interval with end points that depend on all the model parameters but not on net worth. They also show that the Merton (zero transaction cost) solution does not always lie within this optimal interval. This can happen when one endpoint of this interval involves leverage (i.e., 
the optimal portfolio borrows at the risk free rate to invest in the risky asset). In particular, Shreve and Soner (1994) show that "when leverage is optimal, the presence of transaction costs reduces the agent's desire for leverage, and the agent should trade to move from the Merton proportion to a less leveraged position." It appears, therefore, that adjustment costs for debt can move the debt-ratio range downward.

\subsection{Summary}

This section's closed-form solution assumes managers with CRRA utility, decreasing returns to CAPEX, tax-deductible interest and rents, but no financial frictions or financial market imperfections. We recap results here.

1. Decisions about CAPEX, debt, rents and payout are all tied to net worth, that is, to cumulative retained income and equity investment. No decision is independent of the others.

2. Payout and rents move in lockstep. They are smoothed because they depend on cumulative equity income, not on current income. The level of payout and rents depend on whether shareholders would continue the firm as a going concern or shut it down. Higher tax rates increase rents when rents are tax-deductible.

3. The optimal level of capital investment depends on profitability $(+)$, managers' risk aversion (-), managers' cost of rent extraction (-), volatility (-) and the tax rate (+, because a higher tax rate reduces risk to managers). Managers underinvest relative to value-maximizing CAPEX. CAPEX does not depend on managers' personal rate of time preference.

4. Managers may continue to keep the firm alive when profitability is low and assets should be liquidated (regime 3). They overinvest in bad times, not in good times. 
5. There is an optimal net debt ratio that depends on the tax rate $(+)$, volatility (-), managers' risk aversion (-) and costs of rent extraction (-). The optimal ratio can be negative. Debt is safe because it is paid down to maintain the optimal debt ratio when the firm encounters hard times. The value of interest tax shields is not fully exploited. Traditional tradeoff theories of capital structure face difficulties in generating low or negative leverage without assuming unrealistically high bankruptcy costs. But low leverage is a fact of life. For example, Bates, Kahle, and Stulz (2009) report that the median firm in Compustat has a negative net debt ratio. Our model can easily capture negative net debt ratios without assuming any bankruptcy costs, adjustment costs or imperfections in financial markets.

\section{What happens when managers have CARA utility?}

We now consider how our results so far depend on the specification of managers' utility function. It turns out that substituting a plausible alternative function can change managers' financial policies dramatically.

Suppose that managers have negative exponential utility, with $u(r)=\bar{u}-e^{-\eta r}$, where $\bar{u}$ is managers' maximum achievable utility in any given period. This means managers have constant absolute risk aversion (CARA). We assume for simplicity that there are constant returns to scale to investment $(\theta=1)$ and rent extraction $(\nu=1)$.

With CARA utility, the firm's net worth could become negative, which raises the spectre of insolvency and default. Modeling default would add a heavy layer of complexity, rule out a closed-form solution and confuse a comparison of results from the CRRA model. Therefore we assume here that the firm's debt is subject to a net worth covenant, which allows bondholders to liquidate the firm as soon as net worth $N_{t}$ reaches zero. At that point, the firm's debt $D_{t}$ 
equals exactly the firm's capital $K_{t}$. Since net worth follows a diffusion process (no jumps), the covenant ensures that debt remains safe. Shareholders get nothing in liquidation $\left(S\left(N_{t}=\right.\right.$ $0)=0)$ and managers fall back on their life-time reservation utility value $M(N=0)=\underline{U}$.

Finally, we assume that shareholders who intervene and throw out the managers can only run the firm as a going concern. This allows us to compare results to the going-concern regime 1 in the CRRA model.

Managers optimize $M\left(N_{0}\right)=\max _{\left\{r_{t}, K_{t}\right\}} E_{0}\left[\int_{0}^{\infty} e^{-\delta t} u\left(r_{t}\right) d t\right]$ subject to the transversality condition $\lim _{t \rightarrow \infty} E\left[e^{-\delta t} M\left(N_{t}\right)\right]=0$, the value matching condition $M(0)=\underline{U}$ and the intertemporal budget constraint:

$$
d N_{t}=\left[\left(\mu^{*}-\rho^{*}\right) K_{t}+\rho^{*} N_{t}-m r_{t}\right] d t+\sigma^{*} K_{t} d z \equiv g d t+\sigma_{N} d z
$$

This gives the following proposition.

Proposition 4 With negative exponential utility managers' optimal investment $K_{t}$, rent $r_{t}$, and debt $D_{t}$ policies for net worth $N_{t}>0$ are:

$$
\begin{aligned}
K_{t} & =\frac{\left(\mu^{*}-\rho^{*}\right)(1-\tau s)}{\eta \rho^{*} \sigma^{* 2}(1-\alpha)}=\frac{(\mu-\rho)(1-\tau s)}{\eta \rho \sigma^{2}(1-\alpha)(1-\tau)^{2}} \equiv K \\
r_{t} & =\frac{\rho^{*}(1-\alpha)}{(1-\tau s)} N_{t}+\frac{\left(\delta-\rho^{*}\right)}{\eta \rho^{*}}+\frac{\left(\mu^{*}-\rho^{*}\right)^{2}}{2 \eta \rho^{*} \sigma^{* 2}} \\
D_{t} & =K-N_{t}
\end{aligned}
$$

Investment policy is independent of the firm's net debt $D_{t}$ and net worth $N_{t}$. Managers' lifetime utility under the optimal policies is:

$$
\begin{aligned}
M\left(N_{t}\right) & =\frac{\bar{u}}{\delta}-b e^{-\frac{\eta(1-\alpha) \rho^{*}}{(1-\tau s)} N_{t}} \quad \text { for } N_{t}>0 \text { where }: \\
b & =\frac{1}{\rho^{*}} e^{-\frac{1}{\rho^{*}\left[\delta-\rho^{*}+\frac{1}{2} \frac{\left(\mu^{*}-\rho^{*}\right)^{2}}{\sigma^{* 2}}\right]}}
\end{aligned}
$$

At $N_{t}=0$ bondholders close the firm and receive $K$. Shareholders receive nothing and managers receive their lifetime reservation utility, which has been set at $\underline{U} \equiv \frac{\bar{u}}{\delta}-b \underline{2}^{22}$

\footnotetext{
${ }^{22}$ Solving the problem for a general $\underline{U}$ is messy at best, because rents depend on $\underline{U}$ in a complicated way
} 
Managers' utility function has an important effect on CAPEX. With CRRA, the firm's capital stock is constant relative to net worth, but with CARA utility the firm's capital stock is a constant absolute dollar amount.

The optimal net debt ratio is constant with CRRA utility. This is not the case with CARA utility:

Proposition 5 The market value of managers' rents $R_{t}$, outside equity $S_{t}$ and debt $D_{t}$ are:

$$
\begin{aligned}
R_{t} & =A_{0}+A_{1} N_{t}-A_{0} e^{\lambda N_{t}} \\
S_{t} & =\alpha m R_{t} \\
D_{t} & =K-N_{t}
\end{aligned}
$$

where $\lambda$ is the negative root of the characteristic equation $\frac{1}{2} \sigma_{N}^{2} \lambda^{2}+g \lambda-\rho=0$. The firm's net debt ratio is:

$$
N D R_{t}=\frac{D_{t}}{S_{t}+R_{t}+D_{t} I_{d}}=\frac{K-N_{t}}{\left(\frac{1-\alpha \tau s}{1-\alpha}\right)\left[A_{0}+A_{1} N_{t}-A_{0} e^{\lambda N}\right]+\left(K-N_{t}\right) I_{d}}
$$

where $I_{d}=1$ if $D_{t} \geq 0$ and $I_{d}=0$ if $D_{t}<0$. The constants $A_{0}$ and $A_{1}$ are given in the appendix.

With CARA utility, the NDR decreases from 1 to $-\frac{(1-\tau s)}{(1-\alpha \tau)(1-\tau)}$ as $N_{t}$ increases from 0 to $+\infty$. Net debt declines with the firm's net worth, and for sufficiently high levels of $N_{t}\left(N_{t}>K\right)$, the firm has a net cash position.

We now discuss in more detail the firm's investment, payout and financing policies and compare these with the policies we obtained for managers with power utility.

$\overline{\text { (see Karatzas, Lehoczky, Sethi, and Shreve }}(1986)$ ). To obtain an explicit solution we set $\underline{U}$ at the level for which managers' abandonment option has zero value when creditors force closure at $N_{t}=0$. This neutralizes the effects of $\underline{U}$ on the solution. 


\subsection{Investment policy}

With exponential utility, the investment policy is independent of $N_{t}, D_{t}$ and the firm's financing policy. The stock of capital is constant when expected profitability is constant. The capital stock therefore declines as a fraction of net worth when net worth increases. There is a similar result in the portfolio-consumption literature, which shows that the portfolio decision does not depend on the investor's net worth with CARA utility. This is one of the reasons why exponential utility has been a popular choice (see Campbell and Viceira (2002) for a review).

With power utility, by contrast, the stock of capital is linked to net worth. High (low) investment returns cause the firm to scale up (down) its stock of capital. Investment, debt and net worth move together in the same direction: an increase (decrease) in the stock of capital coincides with an increase (decrease) in the amount of debt $D_{t}$ and net worth $N_{t}$.

\subsection{Payout policy}

With CARA utility, rents and payout include a variable and a fixed component. The variable component is a constant fraction of net worth, which depends on the after-tax cost of capital $\rho^{*}$. The fixed component is positive, but decreases with the cost of capital, risk aversion and volatility. Risk aversion therefore reduces the fixed component and encourages managers to save for a rainy day. The fixed component increases with the expected return on capital and managers' discount rate. A higher personal discount rate makes managers less patient and leads to higher rents and payout.

The fixed component is paid out no matter how low $N_{t}$ drops, which means that rents and payout remain strictly positive down to the point where the firm is closed down by lenders - a possible explanation for managers' reluctance to cut (rents and) dividends in bad times. With CARA utility, rents and payout are no longer a constant proportion of net worth. The 
marginal propensity to pay rents out of net worth is $q$ with CRRA and $\rho^{*}(1-\alpha) /(1-\tau s)$ with CARA. The marginal propensity for CARA is typically much smaller than for CRRA ${ }^{23}$ This lower marginal propensity, combined with a positive fixed rent and payout component, implies that CARA utility generates more rent and payout smoothing than CRRA.

\subsection{Debt policy}

Since $D_{t}=K_{t}-N_{t}$ and $K_{t}=K$ is constant with CARA utility, debt and net worth are negatively related. Managers do not disinvest as net worth drops. Substituting the optimal investment and payout policies into the intertemporal budget constraint (40), the net worth process is an arithmetic Brownian motion:

$$
d N_{t}=\frac{m}{\eta \rho^{*}}\left[\frac{\left(\mu^{*}-\rho^{*}\right)^{2}}{2 \sigma^{* 2}}-\delta+\rho^{*}\right] d t+\sigma^{*} K d z_{t}
$$

In the CARA model, cross-sectional differences in debt levels persist indefinitely ${ }^{24}$ Suppose firms 1 and 2 start off with debt levels $D_{10}$ and $D_{20}$ at time $\mathrm{t}=0$. The firms are otherwise identical and absorb the same shocks. The difference in their debt levels will remain constant, i.e. $D_{1 t}-D_{2 t}=D_{10}-D_{20}$. This persistence result is a possible explanation of the empirical findings of Lemmon, Roberts, and Zender (2008).

With CARA utility, debt and profitability are negatively related, as in the pecking order theory of capital structure. The most successful firms pay down debt and accumulate cash. Unsuccessful firms run cash deficits and accumulate more and more debt to cover CAPEX, payout and rents. With CRRA we get the opposite behavior: Successful firms increase the

\footnotetext{
${ }^{23}$ For example: Using the parameter values for Figure 1, the marginal propensity for CARA is $\rho^{*}(1-\alpha) /(1-$ $\tau s)=0.0055$, much less than the marginal propensities for regime 1 plotted in Figure 1C for CRRA.

${ }^{24}$ We know from 49 that the NDR is not constant, but depends on net worth $N_{t}$. Since $N_{t}$ depends on the initial level of net worth $N_{0}$, the NDR depends on $N_{0}$ also. Since $D_{t}=K-N_{t}$ and $N_{t}$ follows an arithmetic Brownian motion, differences in debt remain forever, provided of course that firms are otherwise identical and subject to the same shocks.
} 
stock of risky capital and finance CAPEX with retained earnings (higher $N_{t}$ ) and additional debt. Unsuccessful firms disinvest and use some of the proceeds to repay debt. This causes debt and profitability to be positively related, as in the standard trade-off theory.

With CRRA utility, firms have a constant net debt ratio. Investment, payout and debt all move in lockstep. As a firm grows the dollar amount of risky capital, debt and payout all rise in proportion. Thus small firms are scaled-down versions of their larger counterparts. With CARA utility, small and large firms are very different. Small firms are riskier than large firms, because they have a relatively larger amount of risky capital and more debt. They also pay out more relative to net worth. Larger firms have less debt (or more cash) and a smaller capital stock relative to net worth.

\section{Empirical Implications and Conclusion}

The first sentence of Hennessy and Whited (2007) reads "Corporate finance is primarily the study of financing frictions." But corporate finance is also the study of the financial behavior of managers as agents for outside shareholders. We believe our model is the first dynamic agency model that incorporates all three of the major corporate-finance decisions: investment, borrowing and payout plus managerial rents. We assume rational, risk averse managers, who make these decisions jointly in their long-run self interest, subject to a governance constraint, and also subject to sources and uses of cash adding up in every period. We set aside financialmarket imperfections and financing frictions, except for corporate taxes. Therefore the dynamics of our model are driven by "pure agency." Some of our results deserve further emphasis and discussion.

Our general model (in Section 2) yields several empirical predictions, including:

1. Risk-averse managers invest less than the value-maximizing amount. However, they 
may keep a firm alive that ought to be shut down in order to continue extracting rents. Shareholders' cost of intervention permits managers to run firms that are worth more dead than alive. One could call it overinvestment on the downside.

2. Managers smooth rents and payout, which evolve proportionally. Managers' compensation is tied to payout, similar to dividend unit plans in which executives are compensated on the basis of dividends paid (see Smith and Watts (1982)). Payout and rents depend on the firm's cumulative retained income (net worth) which could be viewed as a payout "reservoir." John and Kalay (1982) report that many firms have covenants that link dividends to cumulative retained earnings.

3. Rent tax shields loosen the governance constraint and allow managers to increase rents relative to payout.

4. Managers do not fully exploit interest tax shields, even though we introduce no financial frictions. There is an optimal net debt ratio that is less than $100 \%$ and possibly even negative. Our agency theory can generate realistic levels of leverage without having to assume financing frictions or costs of financial distress.

The CRRA model set out in Section 3 predicts debt as a constant fraction of net worth a possible explanation for use of book, rather than market debt ratios in practice. But this constant ratio is not pinned down by the usual tradeoff of the marginal values of interest tax shields vs. costs of financial distress. The ratio comes from the managers' joint optimization of CAPEX, borrowing and rents and payout. In this model all these decisions interact; none can be made separately from the others. For example, when net worth declines, managers cut payout and sell some of the firm's risky assets to pay down debt.

But the CARA model in Section 4 generates no stable debt ratio. Instead debt drifts up or down depending on realized profitability, as in a pecking-order model of capital structure. Profitable firms seek to pay down debt. Eventually they accumulate cash and become net 
lenders. Thus the CARA model can explain the "cash mountains" accumulated by the most successful corporations.

The contrast of results from our two closed-form models shows that the financial decisions made by managers in a dynamic setting can change drastically depending on assumptions about managers' preferences. It is not just whether managers are risk-neutral or risk-averse. The type or nature of risk aversion matters.

It is therefore important to know how managers' risk aversion should be modeled. But existing literature offers little or no guidance on this question. Many dynamic models assume that managers seek to maximize market value, which sets agency issues aside and effectively assumes that managers are risk-neutral. The dynamic agency models reviewed in Section 1 all assume risk-neutral managers. Theories from the field of organizational economics typically also assume risk neutrality ${ }^{25}$ The literature on individual investors' consumption-saving decisions and portfolio choices assumes risk aversion, but deploys different utility functions, including both power utility (e.g. Merton (1969, 1971), Constantinides (1986), Viceira (2001)) and negative exponential utility (e.g. Caballero (1990), Angeletos and Calvet (2005)). Absent any guidance from prior work, we must leave the specification of managers' preferences as an important topic for investigation.

Of course our results apply to the mature, public firms that our model is designed for. The predictions could change for firms with highly valuable growth options, for declining firms or for firms facing material risks of financial distress or default (see e.g. Chen, Miao, and Wang $(2010))$.

Extensions of our models could be informative (although the extensions may prevent closed-form solutions). More complex and interesting governance constraints could be ex-

\footnotetext{
${ }^{25}$ Perusal of the Handbook of Organizational Economics by Gibbons and Roberts (2013) turned up no references to models of preferences for teams or hierarchies of risk-averse managers. The typical assumption is risk-neutrality. We thank Robert Gibbons for helpful discussion on this topic.
} 
plored. For example, the governance or sharing parameter $\alpha$ is probably not constant, but higher once the firm has paid off debt and built up a net cash position. Managerial entrenchment comes from investment in specialized assets, not in cash.

Also our managers cannot claim all of NPV, because the fraction $\alpha$ must go to outside shareholders. If, however, the NPV is linked to the managers' human capital and therefore lost if shareholders intervene, then managers could extract the NPV and finance all required $C A P E X$ by cutting back payout or issuing equity. Models built on this premise could help distinguish the financial behavior of growth firms from the behavior of the mature firms analyzed here.

Another open issue is top management compensation. By "top" we mean the CEO and his or her immediate circle, not the much wider group of managers and employees that rents go to. We treat this wider group as a de facto coalition. It is fair to ask how this coalition holds together - see Acharya, Myers and Rajan (2011) for a possible answer - and how individual managers' preferences aggregate in the group.

\section{Appendix}

\section{Proof of proposition 1}

a) Case 1: $F_{t} \geq N_{t}$ (it is optimal for outside investors to keep the firm alive)

From the governance constraint (11), and the definitions for $V_{t}$ and $T_{t}$ (given by (5) and 
(6) it follows that:

$$
\begin{aligned}
S_{t}= & \alpha\left[C F_{t}^{*}+E_{t}\left[\sum_{j=1}^{\infty} \beta^{j} C F_{t+j h}^{*}\right]-(\Gamma(1-\tau)+\tau) D_{t-h}+D_{t}(1-\beta(\Gamma(1-\tau)+\tau))\right] \\
& +\alpha E_{t}\left[\sum_{j=1}^{\infty} \beta^{j} D_{t+j h}(1-\beta(\Gamma(1-\tau)+\tau))\right]=h d_{t}+E_{t}\left[E_{t+h}\left[\sum_{j=1}^{\infty} \beta^{j} C F_{t+j h}^{*}\right]\right] \\
& -\beta(\Gamma(1-\tau)+\tau) D_{t}+E_{t}\left[E_{t+h} \sum_{j=1}^{\infty} \beta^{j} D_{t+j h}(1-\beta(\Gamma(1-\tau)+\tau))\right] \\
& \alpha C F_{t}^{*}-\alpha(\Gamma(1-\tau)+\tau) D_{t-h}+\alpha D_{t}=h d_{t}
\end{aligned}
$$

Replacing $D_{t}$ into (52) by the budget equation $D_{t}=D_{t-1}(\Gamma(1-\tau)+\tau)-C F_{t}^{*}+h d_{t}+$ $h r_{t}(1-\tau s)$, and simplifying, gives equation 12 in proposition 1 .

b) Case 2: $F_{t} \leq N_{t}$ (it is optimal for outside investors to keep the firm alive)

From the governance constraint (11) and the budget constraint (3) it follows that:

$$
\begin{aligned}
S_{t} & =\alpha N_{t}=\alpha\left[K_{t}+h d_{t}+h r_{t}(1-\tau s)+(1-\tau) \Psi-D_{t}\right] \\
& =h d_{t}+\beta E_{t}\left[S_{t+h}\right]=h d_{t}+\beta \alpha\left[K_{t}\left(E_{t}\left[\Pi_{t+h}\right](1-\tau)+\tau\right)-D_{t}(\Gamma(1-\tau)+\tau)\right] \Longleftrightarrow \\
h d_{t} & =\left(\frac{\alpha}{(1-\alpha)}\right)\left\{K_{t}\left[1-\beta E_{t}\left[\Pi_{t+h}\right](1-\tau)-\beta \tau\right]+(1-\tau) \Psi_{t}-\tau(1-\beta) D_{t}+h r_{t}(1-\tau s)\right\}
\end{aligned}
$$

\section{Proof of proposition 2}

Dividing the governance constraint (13) by $h$ on both sides, taking expectations, and taking the limit for $h \rightarrow 0$ gives:

$$
\begin{aligned}
d_{t} & =\frac{\alpha}{(1-\alpha)} \lim _{h \rightarrow 0}\left[r_{t}(1-\tau s)+\frac{(1-\tau) \Psi_{t}}{h}+\frac{K_{t}\left[1-(1-\tau) e^{-\rho h} e^{\mu h}-\tau e^{-\rho h}\right]-\tau D_{t}\left(1-e^{-\rho h}\right)}{h}\right] \\
& =\frac{\alpha}{(1-\alpha)} \lim _{h \rightarrow 0}\left[r_{t}(1-\tau s)+\frac{(1-\tau) \Psi_{t}}{h}-K_{t}(\mu-\rho)(1-\tau) e^{(\mu-\rho) h}+\rho \tau K_{t} e^{-\rho h}-\rho \tau e^{-\rho h} D_{t}\right] \\
& =\left(\frac{\alpha}{(1-\alpha)}\right)\left[r_{t}(1-\tau s)+\lim _{h \rightarrow 0} \frac{(1-\tau) \Psi_{t}}{h}+(\rho-\mu(1-\tau)) K_{t}-\rho \tau D_{t}\right]
\end{aligned}
$$

Finally, substituting $\Psi_{t}$ by the cost function $h \phi K_{t}\left(\frac{K_{t}}{N_{t}}\right)^{\theta-1}$ gives equation 25.

\section{Proof of proposition 3}

We first derive the process for the firm's net worth process $N_{t}$ under the 3 regimes. 
In regime 1 the governance constraint corresponds to $d_{t}=\alpha m r_{t}$. Substituting into (27) the process for $N_{t}$ becomes:

$$
d N_{t}=\left[k_{1}\left(\mu-\rho-\phi\left(\frac{K_{1 t}}{N_{t}}\right)^{\theta-1}\right) K_{1 t}+n_{1} \rho N_{t}-m r_{1 t}\right] d t+\sigma^{*} K_{1 t} d z
$$

where $k_{1} \equiv 1-\tau$ and $n_{1} \equiv 1-\tau$.

In regime 2 the governance constraint imposes the conditions $d_{t}=\alpha m r_{t}$ and $K_{t}(\rho-\mu(1-$ $\tau))-\rho \tau D_{t}+(1-\tau) \phi K_{t}\left(\frac{K_{t}}{N_{t}}\right)^{\theta-1}=0$. The latter constraint pins down the investment policy, and is equivalent to:

$$
\left(\frac{K_{2 t}}{N_{t}}\right)(1-\tau)\left[\mu-\rho-\phi\left(\frac{K_{2 t}}{N_{t}}\right)^{\theta-1}\right]=\rho \tau
$$

This gives equation (31) in proposition 3. Substituting into (27) the process for $N_{t}$ becomes:

$$
d N_{t}=\left[k_{2}\left(\mu-\rho-\phi\left(\frac{K_{2 t}}{N_{t}}\right)^{\theta-1}\right) K_{2 t}+n_{2} \rho N_{t}-m r_{2 t}\right] d t+\sigma^{*} K_{2 t} d z
$$

where $k_{2} \equiv 0$ and $n_{2} \equiv 1$.

In regime 3 the governance constraint imposes condition (25). Substituting into (27) the process for $N_{t}$ becomes:

$$
d N_{t}=\left[k_{3}\left(\mu-\rho-\phi\left(\frac{K_{3 t}}{N_{t}}\right)^{\theta-1}\right) K_{3 t}+n_{3} \rho N_{t}-m r_{3 t}\right] d t+\sigma^{*} K_{3 t} d z
$$

where $k_{3} \equiv(1-\tau) /(1-\alpha)$ and $n_{3} \equiv(1-\alpha-\tau) /(1-\alpha)$.

Applying Bellman's principle of optimality and Ito's lemma, from the theory of stochastic optimal control it is known (see e.g. Merton $(1969,1971)$ ) that for an infinite time horizon the value function $M_{i}$ satisfies the following Hamilton-Jacobi-Bellman differential equation:

$$
\begin{aligned}
\delta M_{i}\left(N_{t}\right)= & \max _{K_{i t}, r_{i t}}\left\{u\left(r_{i t}\right)+\left[k_{i}\left(\mu-\rho-\phi\left(\frac{K_{i t}}{N_{t}}\right)^{\theta-1}\right) K_{t}+n_{i} \rho N_{t}-m r_{i t}\right] \frac{\partial M_{i}}{\partial N_{t}}\right. \\
& \left.+\frac{1}{2} \sigma^{* 2} K_{i t}^{2} \frac{\partial^{2} M_{i}}{\partial N_{t}^{2}}\right\} \quad \text { for } i=1,2 \text { or } 3
\end{aligned}
$$

and where $k_{i}$ and $n_{i}$ are as previously defined. Note that in regime $2(\mathrm{i}=2)$, the variable $K_{2 t}$ is no longer a control variable as it is already determined by the constraint (54). Given 
managers' power utility function and the homogeneity of the problem it follows that $M_{i}$ must be proportional to $N_{t}^{\gamma} / \gamma$. We therefore conjecture the following solution for managers' value function: $M_{i}\left(N_{t}\right)=b_{i} N_{t}^{\gamma} / \gamma$, where $b_{i}$ is a constant that remains to be determined for each of the three regimes $(\mathrm{i}=1,2,3)$.

The first order condition for rents is given by:

$$
u^{\prime}\left(r_{i t}\right)=m \frac{\partial M_{i}}{\partial N} \Longleftrightarrow r_{i t}=\left(\frac{m b_{i}}{\nu}\right)^{\frac{1}{\gamma-1}} N_{t} \equiv q_{i} N_{t} \quad \text { for } i=1,2,3
$$

The first order condition for investment in regimes 1 and 3 is:

$$
\begin{aligned}
& k_{i}\left(\mu-\rho-\theta \phi\left(\frac{K_{i t}}{N_{t}}\right)^{\theta-1}\right) \frac{\partial M_{i}(N)}{\partial N_{t}}+\sigma^{* 2} K_{i t} \frac{\partial^{2} M_{i}(N)}{\partial N_{t}^{2}}=0 \\
\Longleftrightarrow & k_{i}\left(\mu-\rho-\theta \phi\left(\frac{K_{i t}}{N_{t}}\right)^{\theta-1}\right)+\sigma^{* 2}(\gamma-1)\left(\frac{K_{i t}}{N_{t}}\right)=0 \text { for } i=1,3
\end{aligned}
$$

which gives the optimality condition 30 . In what follows define $l_{i}=l_{i t} \equiv \frac{K_{i t}}{N_{t}}$. Substituting the solution for $M_{i}$ and $r_{i t}$ into (57) gives:

$$
\begin{aligned}
0= & \frac{\nu}{\gamma}\left(\frac{b_{i} m}{\nu}\right)^{\frac{\gamma}{\gamma-1}} N^{\gamma}-\frac{\delta b_{i} N^{\gamma}}{\gamma}+\frac{1}{2} \sigma^{* 2} K_{i t}^{2}(\gamma-1) b_{i} N^{\gamma-2} \\
& +\left[k_{i}\left(\mu-\rho-\phi l_{i}{ }^{\theta-1}\right) l_{i} N_{t}+n_{i} \rho N_{t}-m\left(\frac{b_{i} m}{\nu}\right)^{\frac{1}{\gamma-1}} N_{t}\right] b_{i} N^{\gamma-1} \text { for } i=1,2,3
\end{aligned}
$$

Dividing by $b_{i} N^{\gamma}$ and simplifying gives equation (35) which determines $b_{i}$ for regimes 1,2 and 3.

Next, we verify the second order condition for the optimal rent and investment policies. For regimes 1 and 3 the second order condition for a maximum requires that $u^{\prime \prime}\left(r_{t}\right)<0$ and that the determinant of the Hessian is positive, i.e.:

$$
\begin{aligned}
& u^{\prime \prime}\left(r_{t}\right)\left[k_{i}(1-\theta) \phi \theta \frac{K_{i t}{ }^{\theta-2}}{N^{\theta-1}}-\frac{\sigma^{* 2}(1-\gamma)}{N_{t}}\right]>0 \text { for } i=1,3 \\
\Longleftrightarrow & k_{i}(1-\theta) \phi \theta\left(\frac{K_{i t}}{N_{t}}\right)^{\theta-2}<\sigma^{* 2}(1-\gamma) \text { for } u^{\prime \prime}\left(r_{t}\right)<0
\end{aligned}
$$

Since $k_{i} \geq 0, \gamma<1$ and $\theta \geq 1$, it follows that the second order condition is satisfied for regimes 1 and 3 . In regime 2 the investment policy is determined by the governance constraint. Only 
rents are freely chosen. Consequently, the second order condition is given by $u^{\prime \prime}\left(r_{t}\right)<0$, which is always satisfied.

Next, we verify the transversality condition $\lim _{t \rightarrow \infty} E\left[e^{-\delta t} M\left(N_{t}\right)\right]=0$. Under the optimal rent and investment policies the process for $N_{t}$ is given by: $d N_{t}=g_{i} N_{t} d t+\sigma_{i N} N_{t} d z$ where:

$$
g_{i} \equiv\left[k_{i}\left(\mu-\rho-\phi l_{i}^{\theta-1}\right) l_{i}+n_{3} \rho-m q_{i}\right] \text { and } \sigma_{i N} \equiv \sigma^{*} l_{i}
$$

Define $y_{t} \equiv N_{t}^{\gamma}$. Applying Ito's lemma it follows that:

$$
d y=\left[\gamma g_{i}-0.5 \gamma(1-\gamma) \sigma^{2}{ }_{i N}\right] y d t+\gamma \sigma_{i N} y d z
$$

Hence it follows that the transversality condition becomes:

$$
\begin{aligned}
\lim _{t \rightarrow \infty} E_{0}\left[e^{-\delta t} M\left(N_{t}\right)\right] & =\lim _{t \rightarrow \infty} \frac{b_{i}}{\gamma} y_{0} e^{\left[\gamma g_{i}-0.5 \gamma(1-\gamma) \sigma_{i N}^{2}-\delta\right] t}=0 \\
\Longleftrightarrow \gamma\left[g_{i}-\frac{1}{2}(1-\gamma) \sigma_{i N}^{2}\right] & <\delta
\end{aligned}
$$

The transversality condition imposes a restriction on the rate of growth of the net worth process under the optimal policies. We also verify that the market values $R_{t}$ and $S_{t}$ are bounded. $R_{t}$ and $S_{t}$ are given by:

$$
\begin{aligned}
R_{i t} & =E_{t}\left[\int_{t}^{\infty} e^{-\rho u} r_{i u} d u\right]=E_{t}\left[\int_{t}^{\infty} e^{-\rho u} q_{i} N_{u} d u\right]=\frac{q_{i} N_{t}}{\rho-g_{i}} \\
S_{1 t} & =\alpha m R_{1 t} \text { and } S_{2 t}=S_{3 t}=\alpha N_{t}
\end{aligned}
$$

Imposing the growth condition $\rho>g_{i}$ ensures that all market values are bounded.

Next, we calculate the critical values for $\mu$ that separate the regimes 1,2 and 3 , corresponding, respectively, to $F_{t}>N_{t}, F_{t}=N_{t}$ and $F_{t}<N_{t}$. We know that $F_{t}=S_{t}+(1-\tau s) R_{t}$. The going concern value in regime $1, F_{1 t}$, is increasing in $\mu$ whereas the liquidation value $N_{t}$ is independent of $\mu$. Let $\hat{\mu}$ denote the expected return on assets for which $F_{1 t}$ and $N_{t}$ intersect. The critical threshold $\hat{\mu}$ that separates regimes 1 and 2 is the solution to:

$$
\begin{aligned}
F_{1 t} & =S_{1 t}+(1-\tau s) R_{1 t}=R_{1 t}[\alpha m+1-\tau s]=m R_{t}=\frac{m q_{1} N_{t}}{\rho-g_{1}}=N_{t} \\
\Longleftrightarrow \quad m q_{1} & =\rho-g_{1} \Longleftrightarrow \rho \tau=(1-\tau)\left(\hat{\mu}-\rho-\phi l_{1}^{\theta-1}\right) l_{1}
\end{aligned}
$$


where $l_{1}$ is itself a function of $\hat{\mu}$.

The going concern value in regime $3 F_{3 t}$ is increasing in $\mu$. The critical threshold $\bar{\mu}$ that separates regimes 2 and 3 is the solution to:

$$
\begin{gathered}
F_{3 t}=\alpha N_{t}+\frac{(1-\tau s) q_{3}}{\rho-g_{3}} N_{t}=N_{t} \\
\Longleftrightarrow \quad m q_{3}=\rho-g_{3} \Longleftrightarrow \rho \tau=(1-\tau)\left(\bar{\mu}-\rho-\phi l_{3}{ }^{\theta-1}\right) l_{3}
\end{gathered}
$$

where $l_{3}$ is itself a function of $\bar{\mu}$. It follows immediately that $\hat{\mu}$ and $\bar{\mu}$ do not depend on $N_{t}$. Therefore, changes in $N_{t}$ do not lead to regime switches.

Next, define $f(l) \equiv\left(\mu-\rho-\phi l^{\theta-1}\right) l$. It follows that $f^{\prime}(l)>0 \Longleftrightarrow l<\left(\frac{\mu-\rho}{\phi \theta}\right)^{\frac{1}{\theta-1}} \equiv l^{o}$, which is satisfied since the first-best investment level $l^{o}$ is the highest possible investment level. Since $k_{1} \equiv 1-\tau<k_{3} \equiv(1-\tau) /(1-\alpha)$, it follows from 30 that $l_{1}(\mu)<l_{3}(\mu)$ for any given $\mu$. Since $f^{\prime}(l)>0$, it then follows from $(70)$ and $(72)$ that $\bar{\mu}<\hat{\mu}$.

Finally, we prove that both governance constraints bind for $\mu \in] \bar{\mu}, \hat{\mu}[$. We know from (30) and (31) that $l_{1}(\mu)<l_{2}(\mu)<l_{3}(\mu)$ for $\left.\mu \in\right] \bar{\mu}, \hat{\mu}\left[\right.$. Consider the optimal solution $l_{2}(\mu)$. Suppose first that the going concern constraint does not bind, and that managers optimize subject to the liquidation constraint only. In that case investment would rise from $l_{2}(\mu)$ to $l_{3}(\mu)$ and the going concern value would become $F_{3}(\mu)>N_{t}$ since $\mu>\bar{\mu}$. But now the liquidation constraint no longer binds, and therefore the solution cannot be optimal from managers' viewpoint. Suppose next that the liquidation constraint does not bind, and that managers optimize subject to the going concern constraint only. In that case investment would drop from $l_{2}(\mu)$ to $l_{1}(\mu)$ and the going concern value would become $F_{1}(\mu)<N_{t}$ since $\mu<\hat{\mu}$. But now the liquidation constraint is violated and outsiders would intervene. Therefore a solution where either the liquidation constraint or either the going concern constraint binds, but not both, cannot be an equilibrium for $\mu \in] \bar{\mu}, \hat{\mu}[$.

\footnotetext{
${ }^{26}$ Likewise, equations $\sqrt{70}$ and $(72)$ also define the critical thresholds $\hat{\tau}$ and $\bar{\tau}$ if we take $\mu$ as fixed. We refer to the online appendix D for an example.
} 


\section{Proof of proposition 4}

Given the process 40 for $N_{t}, M\left(N_{t}\right)$ must satisfy the following Hamilton-Jacobi-Bellman differential equation:

$$
\delta M\left(N_{t}\right)=\max _{K_{t}, r_{t}}\left\{u\left(r_{t}\right)+\left[\left(\mu^{*}-\rho^{*}\right) K_{t}+\rho^{*} N_{t}-m r_{t}\right] \frac{\partial M}{\partial N}+\frac{1}{2} \sigma^{* 2} K_{t}^{2} \frac{\partial M^{2}}{\partial N^{2}}\right\}
$$

The optimal rent and investment policies are the solution to:

$$
\begin{aligned}
u^{\prime}\left(r_{t}\right) & =m \frac{\partial M}{\partial N_{t}} \\
\sigma^{* 2} K_{t} \frac{\partial^{2} M}{\partial N_{t}^{2}} & =-\left(\mu^{*}-\rho^{*}\right) \frac{\partial M}{\partial N_{t}}
\end{aligned}
$$

Given managers' negative exponential utility function, we conjecture the following solution for $M\left(N_{t}\right)$, and determine the conditions under which this is indeed the solution:

$$
\begin{array}{ll}
M\left(N_{t}\right)=\bar{U}-b e^{-a N_{t}} & \text { for } N_{t}>0 \\
M\left(N_{t}\right)=\underline{U} & \text { for } N_{t} \leq 0
\end{array}
$$

where $a, b, \bar{U}$ and $\underline{U}$ are constants that remain to be determined. Substituting the conjectured solution for $M\left(N_{t}\right)$ into the optimality conditions for $r_{t}$ and $K_{t}$ gives:

$$
\begin{aligned}
r_{t} & =\frac{a}{\eta} N_{t}-\frac{1}{\eta} \ln \left(\frac{m a b}{\eta}\right) \\
K_{t} & =\frac{\mu^{*}-\rho^{*}}{a \sigma^{* 2}} \equiv K
\end{aligned}
$$

It follows immediately that the optimal investment policy is constant, independent of $N_{t}$ and $D_{t}$ and therefore also independent of the firm's financing policy. The second order condition for a maximum requires that $u^{\prime \prime}\left(r_{t}\right)<0$ and that the determinant of the Hessian is positive, i.e.:

$$
\sigma^{* 2} u^{\prime \prime}\left(r_{t}\right)(-1) a^{2} b e^{-a N_{t}}>0 \Longleftrightarrow b>0
$$

Since $u^{\prime \prime}\left(r_{t}\right)<0$, the second order condition is satisfied if $b>0$, which we verify below. 
Substituting the solution into the fundamental optimality equation gives:

$$
\begin{gathered}
\bar{u}-\frac{m a b}{\eta} e^{-a N_{t}}-\delta \bar{U}+\delta b e^{-a N_{t}}-\frac{1}{2} \sigma^{* 2} K^{2} a^{2} b e^{-a N_{t}} \\
+\left[\left(\mu^{*}-\rho^{*}\right) K+\rho^{*} N_{t}-\frac{m a}{\eta} N_{t}+\frac{m}{\eta} \ln \left(\frac{m a b}{\eta}\right)\right] a b e^{-a N_{t}}=0
\end{gathered}
$$

For this equation to be satisfied for all $N_{t}$ we have to impose the following conditions:

$$
\begin{aligned}
\bar{U} & =\frac{\bar{u}}{\delta} \\
a & =\frac{\rho^{*} \eta}{m} \\
0 & =\delta-\frac{m a}{\eta}-\frac{1}{2} \sigma^{* 2} K^{2} a^{2}+\left(\mu^{*}-\rho^{*}\right) K a+\frac{m a}{\eta} \ln \left(\frac{m a b}{\eta}\right)
\end{aligned}
$$

The first and second equation pin down $\bar{U}$ and $a$, respectively, whereas the third equation determines $b$. Solving 85 for $b$ gives:

$$
b=\frac{1}{\rho^{*}} e^{-\frac{1}{\rho^{*}}\left[\delta-\rho^{*}+\frac{1}{2} \frac{\left(\mu^{*}-\rho^{*}\right)^{2}}{\sigma^{* 2}}\right]}>0
$$

Since $b>0$ this verifies the second order condition.

The value matching condition requires that $M(0)=\bar{U}-b=\underline{U}$. We therefore impose the following constraint on managers' outside utility: $\underline{U}=\frac{\bar{u}}{\delta}-b$.

Finally, we prove that the transversality condition $\lim _{t \rightarrow \infty} E\left[e^{-\delta t} M\left(N_{t}\right)\right]=0$ is satisfied. Under the optimal rent and investment policies the process for $N_{t}$ is given by: $d N_{t}=g d t+$ $\sigma_{N} d z$ where:

$$
\begin{aligned}
g & \equiv \frac{\left(\mu^{*}-\rho^{*}\right)^{2} m}{\eta \rho^{*} \sigma^{* 2}}+\frac{m}{\eta} \ln \left(b \rho^{*}\right)=\frac{\left(\mu^{*}-\rho^{*}\right)^{2} m}{2 \eta \rho^{*} \sigma^{* 2}}-\frac{m\left(\delta-\rho^{*}\right)}{\eta \rho^{*}} \\
\sigma_{N} & \equiv \frac{\left(\mu^{*}-\rho^{*}\right) m}{\eta \rho^{*} \sigma^{*}}
\end{aligned}
$$

Define $y_{t} \equiv e^{-a N_{t}}$. Applying Ito's lemma it follows that:

$$
d y=\left[\frac{1}{2} a^{2} \sigma_{N}^{2}-a g\right] y d t-a \sigma_{N} y d z
$$


Hence it follows that the transversality condition becomes:

$$
\begin{aligned}
& \lim _{t \rightarrow \infty} E_{0}\left[e^{-\delta t} M\left(N_{t}\right)\right]=\lim _{t \rightarrow \infty} b y_{0} e^{\left[\frac{1}{2} a^{2} \sigma_{N}^{2}-a g-\delta\right] t}=0 \\
\Longleftrightarrow & \frac{1}{2} a^{2} \sigma_{N}^{2}-a g-\delta<0 \\
\Longleftrightarrow & \frac{\eta^{2} \rho^{* 2}\left(\mu^{*}-\rho^{*}\right)^{2}}{2 m^{2} \eta^{2} \rho^{* 2} \sigma^{* 2}}-\frac{\eta \rho^{*}}{m}\left[\frac{\left(\mu^{*}-\rho^{*}\right)^{2} m}{2 \eta \rho^{*} \sigma^{* 2}}-\frac{m\left(\delta-\rho^{*}\right)}{\eta \rho^{*}}\right]-\delta<0 \Longleftrightarrow-\rho^{*}<0
\end{aligned}
$$

Hence, the transversality condition is satisfied.

\section{Proof of proposition 5}

If investors are risk neutral then the market value of managers' rents must satisfy the following equilibrium condition:

$$
\rho R_{t}=r_{t}+\left.\frac{d}{d \Delta} E_{t} R_{t+\Delta}\right|_{\Delta=0}
$$

Under the assumption that $R_{t}$ is a twice continuously differentiable function of $N_{t}$ application of Ito's lemma gives:

$$
\rho R\left(N_{t}\right)=\frac{\rho^{*}}{m} N_{t}-\frac{1}{\eta} \ln \left(b \rho^{*}\right)+g R^{\prime}\left(N_{t}\right)+\frac{1}{2} \sigma_{N}^{2} R^{\prime \prime}\left(N_{t}\right)
$$

where $g$ and $\sigma_{N}$ are defined in (87) and (88), respectively. The general solution to the o.d.e. is:

$$
R\left(N_{t}\right)=A_{0}+A_{1} N_{t}+A_{2} e^{\lambda N_{t}}+A_{3} e^{\kappa N_{t}}
$$

Substituting into the o.d.e. gives:

$$
\begin{aligned}
& \rho A_{0}+\rho A_{1} N_{t}+\rho A_{2} e^{\lambda N_{t}}+\rho A_{3} e^{\kappa N_{t}}=\frac{\rho^{*}}{m} N_{t}-\frac{1}{\eta} \ln \left(b \rho^{*}\right)+g A_{1} \\
& +g \lambda A_{2} e^{\lambda N_{t}}+\frac{1}{2} \sigma_{N}^{2} \lambda^{2} A_{2} e^{\lambda N_{t}}+g \kappa A_{3} e^{\kappa N_{t}}+\frac{1}{2} \sigma_{N}^{2} \kappa^{2} A_{3} e^{\kappa N_{t}}
\end{aligned}
$$

It follows that $\rho A_{1}=\frac{\rho^{*}}{m}$, or equivalently $A_{1}=\frac{1-\tau}{m}$ and that:

$$
\begin{aligned}
A_{0} & =\frac{g}{\rho} A_{1}-\frac{1}{\eta \rho} \ln \left(b \rho^{*}\right)=\frac{g(1-\tau)}{m \rho}-\frac{1}{\rho \eta} \ln \left(b \rho^{*}\right) \\
\rho & =g \lambda+\frac{1}{2} \sigma_{N}^{2} \lambda^{2} \\
\rho & =g \kappa+\frac{1}{2} \sigma_{N}^{2} \kappa^{2}
\end{aligned}
$$


Let $\lambda$ and $\kappa$ be, respectively, the negative and positive root of the above quadratic equation.

Since the firm does not have any growth options, it must be the case that $\lim _{N_{t} \rightarrow+\infty} R\left(N_{t}\right)=$ $A_{0}+A_{1} N_{t}$ and therefore $A_{3}=0$. Next, upon closure at $N_{t}=0$ managers receive no further rents, i.e. $R(0)=0$. Hence, the value matching condition at $N_{t}=0$ requires that $R(0)=A_{0}+A_{2}=0$ or equivalently: $A_{2}=-A_{0}$, which completes the solution for $R\left(N_{t}\right)$. Finally, since $d_{t}=\alpha m r_{t}$, it follows immediately that $S_{t}=\alpha m R_{t}$.

\section{References}

Acharya, V., S. C. Myers, and R. G. Rajan (2011): "The Internal Governance of Firms," Journal of Finance, 66, 689-720.

Angeletos, G.-M., And L.-E. Calvet (2005): "Incomplete-market Dynamics in a Neoclassical Production Economy," Journal of Mathematical Economics, 41(45), 407-438.

(2006): "Idiosyncratic production risk, growth and the business cycle," Journal of Monetary Economics, 53(6), 1095-1115.

Bates, T. W., K. M. Kahle, and R. M. Stulz (2009): "Why do U.S. firms hold so much more cash than they used to?," Journal of Finance, 64(5), 1985-2021.

Bickley, J. M. (2012): "Employee Stock Options: Tax Treatment and Tax Issues," CRS report for congress RL31458, Congressional Research Service.

Bolton, P., H. Chen, And N. Wang (2011): "A unified theory of Tobins q, corporate investment, financing, and risk management," Journal of Finance, 66(5), 1545-1578.

Bolton, P., And M. Dewatripont (2005): Contract Theory. Mit Press, Cambridge, MA.

Brav, A., J. R. Graham, C. R. Harvey, and R. Michaely (2005): "Payout policy in the 21st century," Journal of Financial Economics, 77, 483-528. 
Caballero, R. J. (1990): "Consumption Puzzles and Precautionary Savings," Journal of Monetary Economics, 25, 113-136.

Campbell, J. Y., And L. M. Viceira (1999): "Consumption and Portfolio Decisions When Expected Returns Are Time Varying," The Quarterly Journal of Economics, 114(2), 433-495. (2002): Strategic Asset Allocation: Portfolio Choice for Long-term Investors. Oxford University Press, New York.

Chen, H., J. Miao, And N. Wang (2010): "Entrepreneurial finance and nondiversifiable risk," Review of Financial Studies, 23(12), 4348-4388.

Constantinides, G. M. (1986): "Capital Market Equilibrium with Transaction Costs," Journal of Political Economy, 94(4), 842-862.

Davis, M. H., AND A. R. Norman (1990): "Portfolio Selection with Transaction Costs," Mathematics of Operations Research, 15(4), 676-713.

DeAngelo, H., L. DeAngelo, And T. Whited (2011): "Capital Structure Dynamics and Transitory Debt," Journal of Financial Economics, 99, 235-261.

DeMarzo, P., And M. Fishman (2007): "Agency and optimal investment dynamics," Review of Financial Studies, 20(1), 151-188.

Demarzo, P. M., M. J. Fishman, Z. He, And N. Wang (2012): "Dynamic Agency and the q Theory of Investment," Journal of Finance, 67, 2295-2340.

Décamps, J.-P., S. Gryglewicz, E. Morellec, and S. Villeneuve (2016): “Corporate Policies with Permanent and Transitory Shocks," Review of Financial Studies, 30(1), 162-210.

Décamps, J.-P., T. Mariotti, J.-C. Rochet, and S. Villeneuve (2011): "Free Cash Flow, Issuance Costs and Stock Prices," Journal of Finance, 66, 1501-1544.

Edmans, A., X. Gabaix, T. Sadzik, and Y. Sannikov (2012): "Dynamic CEO Compensation," Journal of Finance, 67(5), 1603-1647. 
Fluck, Z. (1998): "Optimal Financial Contracting: Debt versus Outside Equity," Review of Financial Studies, 11(2), 383-419.

Gibbons, R., And J. Roberts (2013): The Handbook of Organizational Economics. Princeton University Press, Princeton, New Jersey.

Gryglewicz, S. (2011): "A Theory of Corporate Financial Decisions with Liquidity and Solvency Concerns," Journal of Financial Economics, 99(2), 365-384.

Hennessy, C. A., And T. M. Whited (2005): "Debt Dynamics," Journal of Finance, 60, 11291164.

(2007): "How Costly Is External Financing? Evidence from a Structural Estimation," Journal of Finance, 62(4), 1705-1745.

Jin, L., And S. C. Myers (2006): "R2 around the World: New Theory and New Tests," Journal of Financial Economics, 79, 257-292.

John, K., And A. Kalay (1982): "Costly Contracting and Optimal Payout Constraints," Journal of Finance, 37, 457-470.

Karatzas, I., J. Lehoczky, S. Sethi, and S. Shreve (1986): "Explicit Solution of a General Consumption/investment Problem," Mathematics of Operations Research, 11(2), 261-294.

Lambrecht, B. M., And S. C. Myers (2007): "A Theory of Takeovers and Disinvestment," Journal of Finance, 62(2), 809-845.

(2008): "Debt and Managerial Rents in a Real-Options Model of the Firm," Journal of Financial Economics, 89(2), 209-231.

(2012): “A Lintner Model of Payout and Managerial Rents," Journal of Finance, 67(5), $1761-1810$.

Lambrecht, B. M., And G. Pawlina (2013): "A Theory of Net Debt and Transferable Human Capital," Review of Finance, 17(1), 321-368. 
Lemmon, M., M. Roberts, And J. Zender (2008): "Back to the beginning: Persistence and the cross-section of corporate capital structures," Journal of Finance, 63(4), 1575-1608.

LintneR, J. (1956): "Distribution of Incomes of Corporations among Dividends, Retained Earnings, and Taxes," American Economic Review, 46, 97-113.

Merton, R. C. (1969): "Lifetime portfolio selection under uncertainty: The continuous-time case," The review of Economics and Statistics, pp. 247-257.

(1971): "Optimum consumption and portfolio rules in a continuous-time model," Journal of economic theory, 3(4), 373-413.

Miller, M. (1977): "Debt and Taxes," Journal of Finance, 32(2), 261-275.

Morellec, E. (2004): “Can Managerial Discretion Explain Observed Leverage Ratios?," Review of Financial Studies, 17, 257-294.

Morellec, E., B. Nikolov, And N. Schürhoff (2012): "Corporate Governance and Capital Structure Dynamics," The Journal of Finance, 67(3), 803-848.

Myers, S. C. (2000): "Outside Equity," Journal of Finance, 55(3), 1005-1037.

Ohlson, J. A. (1995): "Earnings, book values, and dividends in equity valuation," Contemporary accounting research, 11(2), 661-687.

SAnnikov, Y. (2013): "Contracts: The theory of dynamic principal-agent relationships and the continuous-time approach," Advances in Economics and Econometrics, 10th World Congress of the Econometric Society.

Shreve, S. E., AND H. M. Soner (1994): "Optimal Investment and Consumption with Transaction Costs," The Annals of Applied Probability, 4(3), 609-692.

Skinner, D. (2008): "The Evolving Relation between Earnings, Dividends, and Stock Repurchases," Journal of Financial Economics, 87(3), 582-609. 
Smith, C. W., And R. L. Watts (1982): "Incentive and Tax Effects of Executive Compensation Plans," Australian Journal of Management, 7(2), 139-157.

Strebulaev, I. A., And T. M. Whited (2012): "Dynamic Models and Structural Estimation in Corporate Finance," Foundations and Trends in Finance, 6, 1-163.

ViceirA, L. (2001): "Optimal Portfolio Choice for Long-Horizon Investors with Nontradable Labor Income," Journal of Finance, 56, 433-470.

Zwiebel, J. (1996): "Dynamic Capital Structure under Managerial Entrenchment," American Economic Review, 86(5), 1197-1215. 
A) Going concern to net worth ratio $\left(F_{t} / N_{t}\right)$

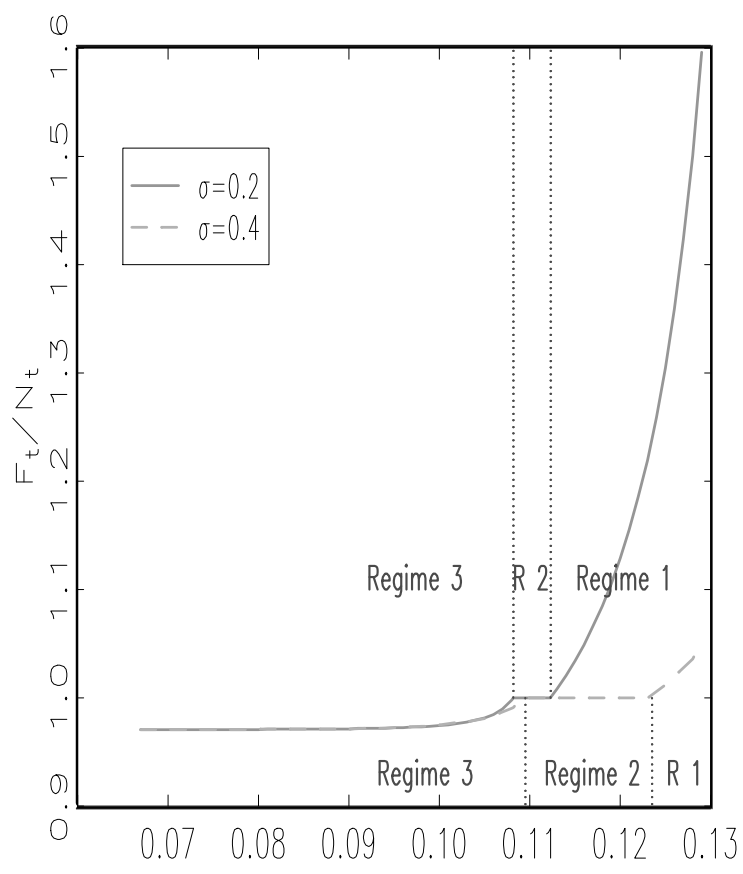

Expected rate of return on risky assets $(\mu)$

c) Optimal Rent to net worth ratio $\left(r_{t} / N_{t}\right)$

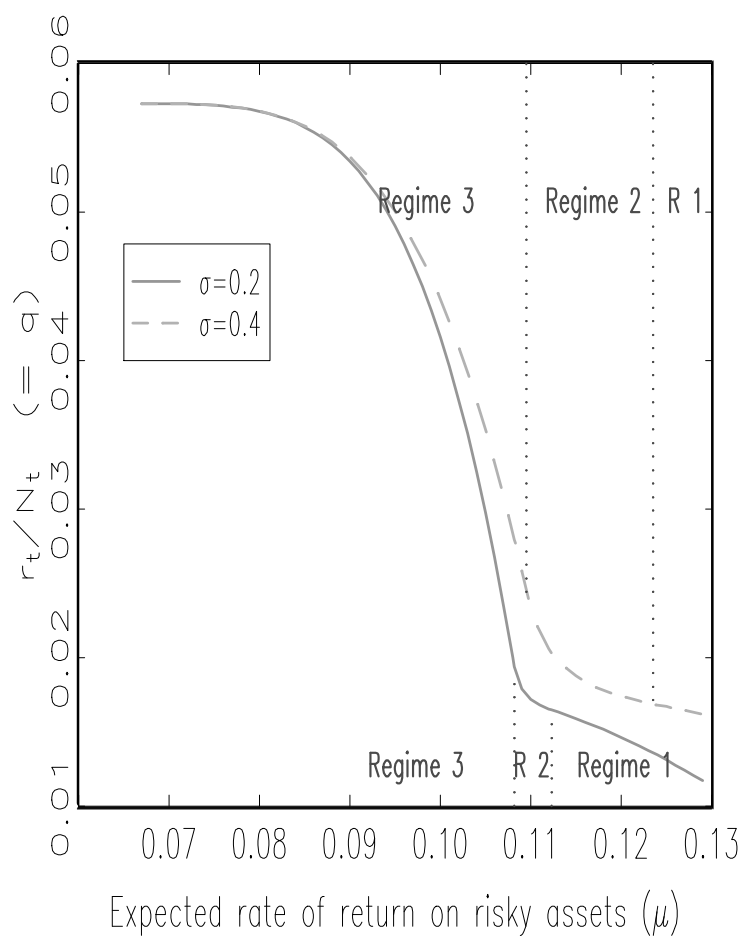

B) Optimal Capital to net worth ratio $\left(K_{t} / N_{t}\right)$

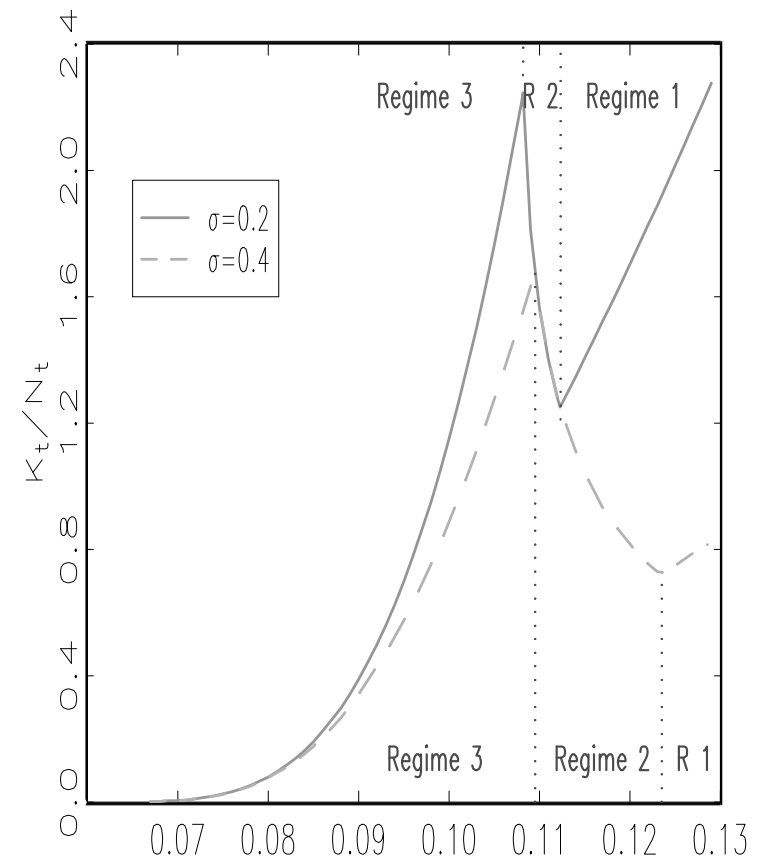

Expected rate of return on risky assets $(\mu)$

D) Optimal Net Debt ratio (NDR)

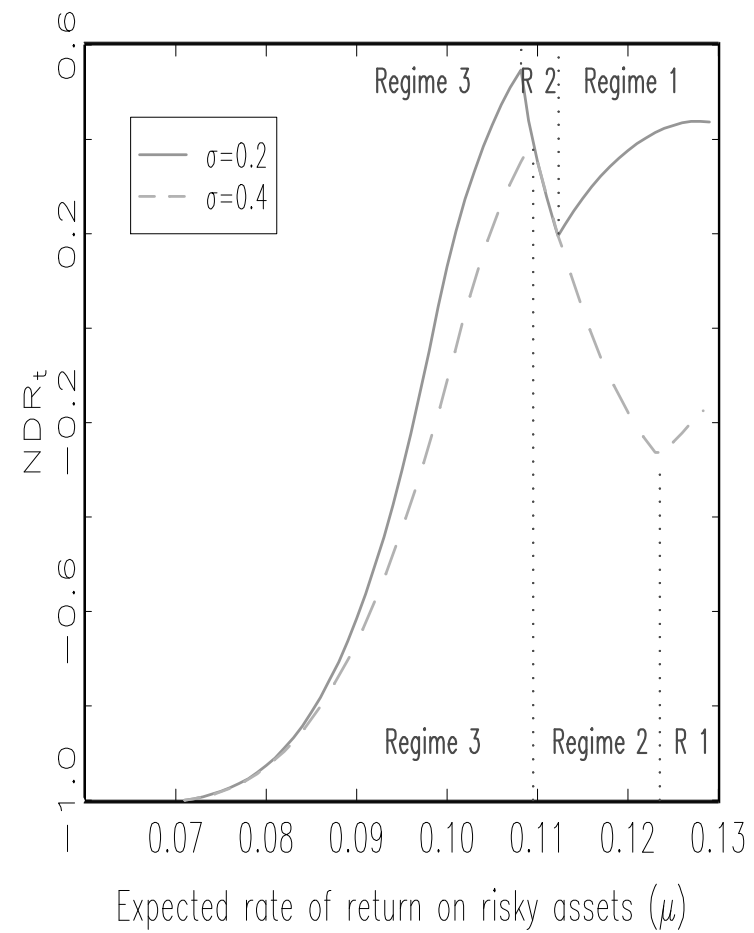

Figure 1: The figure illustrates the effect of the expected rate of return on risky projects $\mu$ on the firm's corporate policies for two different levels of volatility $(\sigma)$. The values for the parameters are: $s=0.8, \rho=0.06, \delta=0.08, \phi=0.03, \eta=0.2, \nu=0.8, \tau=0.3, \theta=1.25$ and $\alpha=0.9$. 
A) Optimal Capital to net worth ratio $\left(K_{t} / N_{t}\right)$

B) Optimal Capital to net worth ratio $\left(K_{t} / N_{t}\right)$
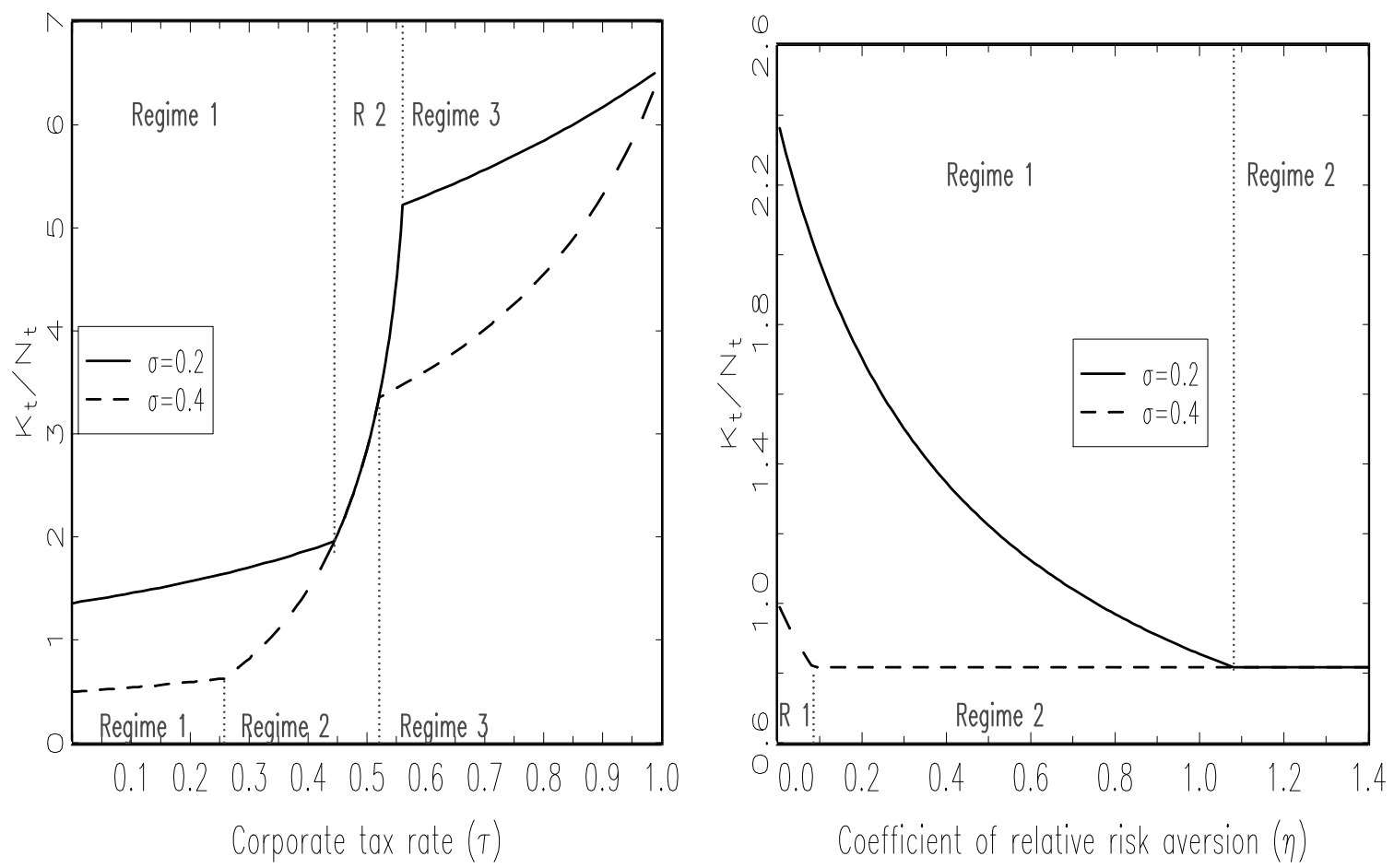

c) Optimal Net Debt ratio (NDR)

D) Optimal Net Debt ratio (NDR)
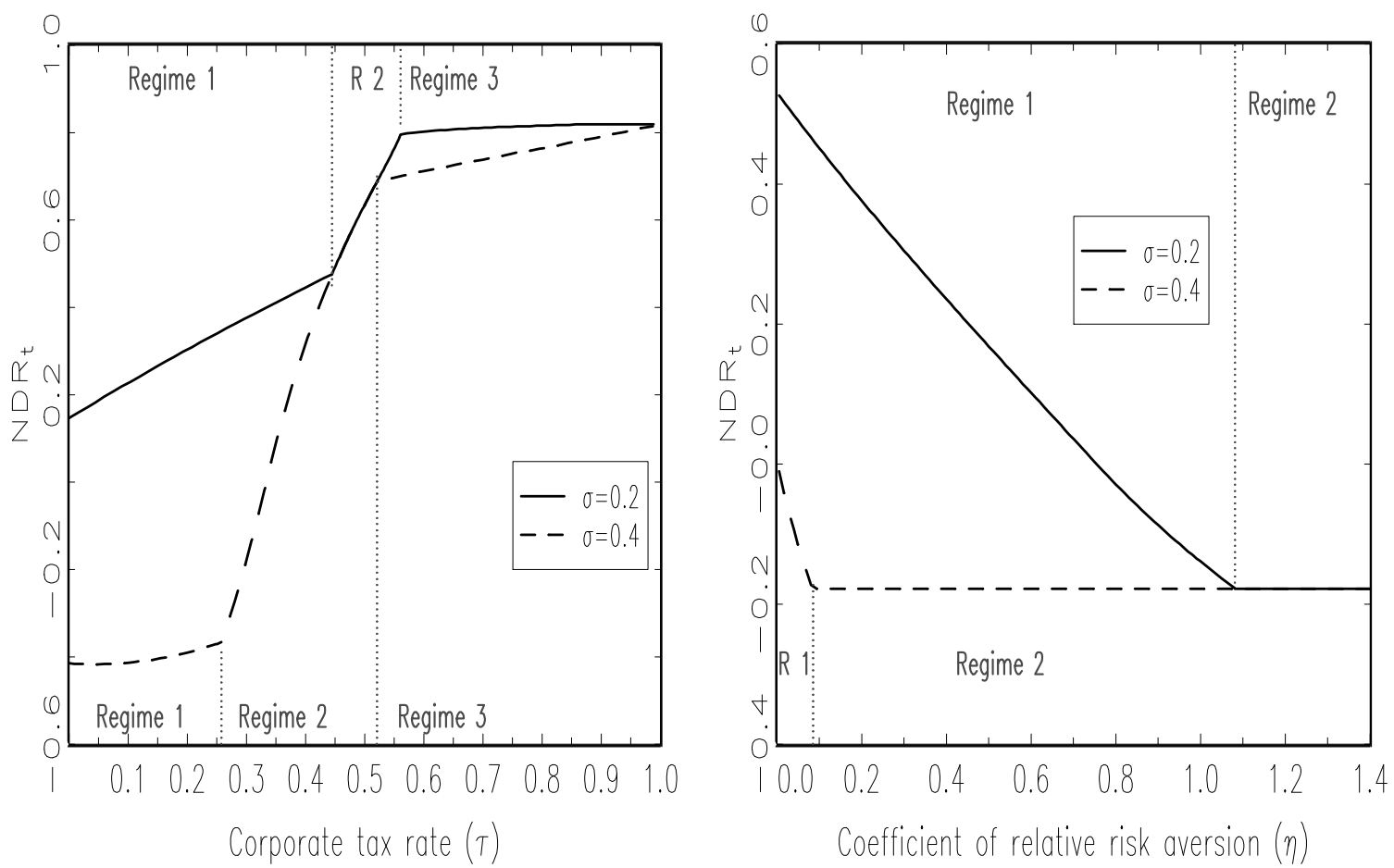

Figure 2: The figure plots the investment and financing policies as a function of the tax rate $(\tau)$ and managers' coefficient of risk $\operatorname{aversion}_{57}(\eta)$ for two different levels of volatility $(\sigma)$. The base parameter values used to generate the plots are: $\mu=0.12, s=0.8, \rho=0.06, \delta=0.08$, $\phi=0.03, \tau=0.3, \eta=0.2, \nu=0.8, \theta=1.25$ and $\alpha=0.9$. 